\title{
Linear combination methods for prediction of drug skin permeation
}

\author{
Stefan Scheler ${ }^{1, \bigotimes}$, Alfred Fahr ${ }^{2}$, Xiangli Liu ${ }^{3}$ \\ ${ }^{1}$ Sandoz GmbH, Biopharmaceuticals, Pharmaceutical \& Device Development, Biochemiestrasse 10, 6336 Langkampfen, \\ Austria \\ ${ }^{2}$ Friedrich Schiller University of Jena, Department of Pharmaceutical Technology, Lessingstr. 8, 07743 Jena, Germany \\ ${ }^{3}$ Bradford School of Pharmacy, University of Bradford, BD7 1DP, UK
}

${ }^{\circledR}$ Corresponding Author: E-mail: stefan.scheler@sandoz.com; Tel.: +43 5372 69962793; Fax: +43 537269965672

Received: November 15, 2014; Revised: December 22, 2014; Published: January 09, 2015

\begin{abstract}
Many in-vitro methods for prediction of skin permeability have been reported in literature. Cerasome electrokinetic chromatography is one of the most sophisticated approaches representing a maximum level of similarity to the lipid phase of the stratum corneum. One goal of this study was to investigate the affinity pattern of Cerasome and to compare it with the permeability profile of human skin. Another purpose was to study the applicability of Hansen solubility parameters for modelling skin permeation and to investigate the predictive and explanatory potential of this method. Visualisation in Hansen diagrams revealed very similar profiles of Cerasome electrokinetic chromatography retention factors and skin permeability coefficients. In both cases, the characteristic pattern with two clusters of highly retained or highly permeable substances could be shown to be mainly caused by two groups of compounds, one of them with high affinity to ceramides, fatty acids and lecithin and the other being more affine to cholesterol. If based on a sufficiently comprehensive experimental dataset, model-independent predictions of skin permeability data using three-component Hansen solubility parameters are able to achieve similar accuracy as calculations made with an Abraham linear free energy relationship model in which the compounds are characterized by seven physicochemical descriptors.
\end{abstract}

Keywords: Cerasome 9005; Liposome electrokinetic chromatography; Linear free energy relationship analysis; Solubility parameter; Stratum corneum

\section{Introduction}

The transdermal administration route is one of oldest, safest, and most convenient for the patient and can be used for both, local and systemic therapy. However, the primary function of the skin is that of a barrier rather than of an absorption organ. An important role is played by the stratum corneum, the outermost layer of the epidermis. It consists of 15-25 layers of non-viable cells, each of which is about 0.2-0.5 mm thick. As they had become cornified in their terminal stage of differentiation, they are mainly composed of keratin. The interstices between these corneocytes are tightly sealed with various lipids, accounting for about 5-15\% of the stratum corneum [1]. Though the stratum corneum is the thinnest layer of the skin at the preferred application sites it is the rate limiting structure for transepidermal drug transport. Disregarding the less pronounced drug penetration via pores (transglandular, transfollicular), two types of transepidermal transport can be distinguished: the transcellular and the intercellular route [2]. In case of the first mentioned type the drug has to pass both, the intercellular lipid layers and the hydrophilic 
cytoplasma and keratin structures, which requires a very well balanced hydrophilicity/lipophilicity ratio of the molecules [3]. Hence, for many drugs and other substances permeation through the skin is mainly accomplished by intercellular transport where the drug diffuses through the lipid filled interstices between the corneocytes [4].

The steady-state flux, $J_{s, v}$ of a drug from a vehicle through the skin can be derived, according to Fick's laws, from the concentration of the drug in the vehicle $\left(c_{v}\right)$ and the permeability coefficient, $k_{\mathrm{p}}[5]$ :

$$
J_{s, v}=k_{p} \cdot c_{v}
$$

$k_{\mathrm{p}}$ is defined as the product of the partition coefficient $\left(P_{\mathrm{s}, \mathrm{v}}\right)$ and the diffusion coefficient $\left(D_{\mathrm{s}}\right)$ divided by the thickness of the skin $\left(h_{s}\right)$ :

$$
k_{p}=\frac{P_{s, v} \cdot D_{s}}{h_{s}} .
$$

Thus $J_{s, v}$ depends on the partition of the drug between the vehicle and the skin. In case of intercellular transport this means partition between the vehicle and the intercellular lipids. It is known that $D_{\mathrm{s}}$ correlates only slightly with the chemical structure of the substance, however $P_{s, v}$ is strongly related to the structural properties of the molecules. Hence, the permeability coefficient of lipid soluble substances is essentially determined by the lipid/water distribution, which is consequently a main factor governing the flux through the skin. The determination of solubilities in stratum corneum lipids poses experimental difficulties, e.g. with respect to a standardized and well defined composition of the mixture. For this reason, the solubility in other lipophilic solvents, most commonly octanol, is used as a surrogate [6]. However, in contrast to stratum corneum lipids, those substances, like aliphatic alcohols or hydrocarbons, are uncharged and do not show similar interactions with electrolytes as they have to be assumed, for example, with stratum corneum fatty acids. In addition, the ordered structure of lipids arranged in membranes might account for a modified affinity to different solutes as compared with a physical mixture of the same lipids.

For this reason, many in-vitro models, mimicking the composition and the structure of human stratum corneum, have been investigated so far in order to mathematically describe the process of skin permeation [7-11]. Likewise, different methods have been studied to analyse the raw data obtained in such experimental setups. Many of these methods aim to predict the skin penetration from chemical, physicochemical or structural data of the compounds without subjecting them to any experimental test. One of these methods is linear free energy relationship analysis (LFER). The study presented here investigates another approach. Based on data obtained from electrokinetic chromatography (LEKC) and human skin permeation, Hansen solubility parameters (HSP) were applied for data analysis, and advantages and disadvantages of this method were studied in comparison to LFER.

As mentioned above, partitioning of the drug into the stratum corneum lipids is only one crucial step in drug skin permeation. Another step is the diffusion through the intercellular space. With in-vitro skin models it is not possible to analyse these processes individually. Quantitative structure-property relationship approaches modelling the drug skin permeation process as a whole do not facilitate a differentiated analysis of individual factors of influence. For this reason LEKC was applied as a model to obtain data reflecting exclusively partitioning into stratum corneum lipids. By separate analysis of both steps, partitioning and diffusion, much deeper insight can be gained regarding the significance and role of involved structures and molecules. 


\section{Theory}

\section{Liposome electrokinetic chromatography (LEKC)}

Chromatographic methods based on immobilized artificial membranes (IAMs, monolayers of phospholipid analogs covalently bonded to the surface of silica particles) and micelles (BMC = biopartitioning micellar chromatography) have been applied to better mimic the lipid structures in the stratum corneum and to improve the prediction of lipid distribution and skin penetration $[7,8]$. One of the most sophisticated techniques in this field is liposome electrokinetic chromatography (LEKC) $[9,10]$. As liposomes possess lipid bilayer structures they resemble biological biomembranes much more than the aforementioned systems. Most studies applying LEKC for studying skin penetration have used conventional phosphatidylcholine (PC)/phosphatidylserine (PS) liposomes which do not reflect the composition of the lipid layers in the stratum corneum. Zhang et al. performed LEKC measurements using Cerasome 9005, a $6.6 \%(\mathrm{w} / \mathrm{w})$ vesicular dispersion composed of hydrogenated lecithin, ceramides (NP and NS), cholesterol and fatty acids (palmitic acid and oleic acid) [11]. The mixture resembles the composition of the stratum corneum lipids which consist of 40-50 \% ceramides, about $25 \%$ sterols, mainly cholesterol, and 10-20\% free fatty acids. However, in contrast to Cerasome, the intercellular stratum corneum lipids are free of phospholipids. Anyway, they form multilamellar sheets as a result of the steric interaction of amphiphilic ceramides with cholesterol and free fatty acids [12-15]. Originally developed and marketed as a prefabricated liposome dispersion for cosmetic and drug formulation, the Cerasome dispersion was used by the cited authors as a running solution in LEKC, in order to model drug partitioning in stratum corneum lipids and consequently skin permeation. With these data, collected from 71 different compounds, they established a quantitative relationship between the structurally determined physicochemical descriptors and the retention factors in LEKC using LFER.

\section{Linear free energy relationship analysis (LFER)}

LFER (and also the very similar LSER = Linear solvation energy relationship [16]) is a type of a quantitative structure-property relationship (QSPR). It represents a mathematical model able to predict physicochemical properties (e.g. permeation, absorption, partitioning, solubility or, in case of this work, LEKC retention factors) from chemical molecular descriptors of a substance. In LFER the logarithm of the physicochemical property depends linearly on a free energy change as also the various descriptors are related to Gibbs free energy. A widely used model, developed by Abraham is based on the following equation,

$$
\log S P=c+e E+s S+a A+b B+v V+j^{+} J^{+}+j^{-} J^{-}
$$

where SP is a free energy-related physicochemical property of a compound in a given solvent system. The lower case letters $\left(e, s, a, b, v, j^{+}, j\right)$ are system constants describing the contribution of the solvent phase to the sorption process [11]. The capital letters are solute descriptors representing the properties of the compounds. In detail, these are the excess molar refraction $(E)$, the solute dipolarity/polarizability $(S)$, the overall solute hydrogen bond acidity $(A)$ and hydrogen bond basicity $(B)$, the McGowan characteristic volume $(V)$, a descriptor for cations $\left(J^{+}\right)$, and another for anions $\left(J^{\prime}\right) . V$ is calculated by summing up all atom volumes of the molecule and subtracting $6.56 \mathrm{~cm}^{3} \mathrm{~mol}^{-1}$ for each bond. Zhang et al. demonstrated that Eq. (3) is able to describe both the retention factors in LEKC and the distribution coefficient at pH $7.4\left(D_{7.4}\right)$ between water and different solvents for all tested compounds including non-ionic and ionic substances [11]. 


\section{Solubility parameters}

Another, quite different approach for computation of solubility related properties is the application of solubility parameters. A main purpose of this study is the comparison of both systems, LFER and solubility parameters, with respect to their ability to predict skin penetration behaviour and the properties of different substances in in-vitro models. In order to work out and to understand analogies and differences between both systems, some general considerations on solubility parameters have to be made first.

The concept of solubility parameters is based on the cohesive energy density (CED) which is the energy per unit volume necessary to separate the molecules of a solute or solvent to a distance where all cohesive interactions have disappeared. The simplest system of solubility parameters $(\delta)$ was introduced by Hildebrand and Scott, who defined them as the square root of the CED:

$$
\delta=\sqrt{C E D}=\left(\Delta E_{v} / V_{m}\right)^{0.5}
$$

where $\Delta E_{\mathrm{v}}$ is the energy of vaporization and $V_{\mathrm{m}}$ is the molar volume [17]. According to Eq. (5), materials having similar solubility parameters have a low non-combinatorial free energy of mixing, $\Delta \mathrm{G}^{\mathrm{M}}{ }_{\text {noncomb}}$, and therefore a high affinity for each other.

$$
\Delta G_{\text {noncomb }}^{M}=\varphi_{1} \varphi_{2} V_{M}\left(\delta_{1}-\delta_{2}\right)^{2}
$$

$\varphi_{1}$ and $\varphi_{2}$ are the volume fractions of the components and $V_{\mathrm{M}}$ is the volume of the mixture. The noncombinatorial free energy of mixing includes all free energy effects other than the combinatorial entropy of solution, occurring because of simple mixing the components [18]. As the free energy of mixing $\left(\Delta G_{M}\right)$ is the difference between the non-combinatorial energy change and the combinatorial entropy change $\left(T \Delta S^{\mathrm{M}}{ }_{\text {comb }}\right)$,

$$
\Delta G^{M}=\Delta G_{\text {noncomb }}^{M}-T \Delta S_{\text {comb }}^{M}
$$

the maximum difference of solubility parameters which is just small enough for solution to occur (i.e. $\Delta G^{M}=0$ ), can be calculated from the condition:

$$
\Delta G_{\text {noncomb }}^{M}=T \Delta S_{\text {comb }}^{M}
$$

It follows from the above that $\Delta G^{M}$ noncomb includes both terms by which $\Delta G^{M}$ of a real solution differs from that of an ideal solution, the excess enthalpy and the excess entropy. When calculating the mole fraction solubility, $X_{2}$, of a substance in a solvent forming a real solution these corrections are accounted for by the rational activity coefficient, $\gamma_{2}$.

$$
-\ln X_{2}=-\ln X_{2}^{i}+\ln \gamma_{2}=\frac{\Delta H_{f}}{R T}\left(\frac{T_{0}-T}{T_{0}}\right)-\frac{\Delta c_{p}}{R}\left[\frac{T_{0}-T}{T}-\ln \left(\frac{T_{0}}{T}\right)\right]+\left[\left(w_{11}\right)^{1 / 2}-\left(w_{22}\right)^{1 / 2}\right]^{2} \frac{V_{2} \Phi_{1}^{2}}{R T}
$$

where $X_{2}{ }^{i}$ is the ideal mole fraction solubility, $\Delta H_{f}$ is the heat of fusion of the solute, $T$ is the temperature and $T_{0}$ is the melting point of the solute, $V_{2}$ is the molar volume of the solute, $\Phi_{1}$ is the volume fraction of the solvent and $R$ is the gas constant. $\Delta c_{p}$ is the difference in heat capacity between the solid form and the hypothetical super-cooled liquid form of the solute. $w_{11}$ and $w_{22}$ are the energy required to generate a void between adjacent solvent molecules and the energy required to overcome the attractive forces between the solute molecules, respectively. The square roots of these energies represent the Hildebrand solubility parameters of the solvent $\left(\delta_{1}\right)$ and the solute $\left(\delta_{2}\right)$. Inserting these parameters, Eq. (8) can be written as 


$$
-\ln X_{2}=\frac{\Delta H_{f}}{R T}\left(\frac{T_{0}-T}{T_{0}}\right)-\frac{\Delta c_{p}}{R}\left[\frac{T_{0}-T}{T}-\ln \left(\frac{T_{0}}{T}\right)\right]+\left(\delta_{1}-\delta_{2}\right)^{2} \frac{V_{2} \Phi_{1}^{2}}{R T}
$$

Most of the compounds investigated in this study are in a solid state at room temperature, however, solubility parameters are based on the enthalpy changes occurring when liquids are mixed. This fact is taken into account by the subtractive term in Eq. (9) which is related to the energy required to convert the solids into the hypothetical super-cooled liquids. Since the heat capacity of the super-cooled liquid normally cannot be determined, it is a common assumption, valid for nonpolar and for polar aprotic solvents, that $\Delta c_{p}$ is small and can be assumed to be zero. This simplifies Eq. (9) to Eq. (10) [19]:

$$
-\ln X_{2}=\frac{\Delta H_{f}}{R T}\left(\frac{T_{0}-T}{T_{0}}\right)+\left(\delta_{1}-\delta_{2}\right)^{2} \frac{V_{2} \Phi_{1}^{2}}{R T} .
$$

Though still widely used, the concept of Hildebrand takes insufficient account of the fact that different types of forces are acting between the molecules in a mixture, all of them contributing to the miscibility and other interaction properties. Many approaches have been made to introduce corrections or to subdivide the Hildebrand parameters into partial solubility parameters dedicated to different types of intermolecular interactions. The most widely used method is a three-component parameter model proposed by C.M. Hansen [18]. He introduced a system of three parameters, $\delta_{d}$, $\delta_{p}$, and $\delta_{h}$, contributing to dispersive (van der Waals), polar and hydrogen-bond interactions, respectively.

$$
\delta_{t}=\delta_{d}+\delta_{p}+\delta_{h}
$$

$\delta_{t}$ is the total solubility parameter which is numerically equal to the Hildebrand parameter. Using only three components, Hansen solubility parameters (HSPs) have the advantage to be visualizable in a threedimensional coordinate system. Another benefit is that HSPs for a huge number of various substances are listed in literature and that group contribution methods allow for estimation of HSP values on the basis of a given structure formula.

Due to its high versatility, the HSP concept has gained widespread use, in many fields of application, like solvent selection, polymer synthesis and engineering, surface characterization, chemical and biological compatibility studies, and even in pharmaceutical development, e.g. in the areas of drug formulation [20-30] or permeability across biological barriers [32,33]. Also the use of solubility parameters (Hansen or Hildebrand) for prediction of skin transport was investigated [5, 34-37].

As the first summand in Eq. (10) is the ideal mole fraction solubility $X_{2}{ }^{i}$, the logarithm of the rational activity coefficient $\ln \gamma_{2}$ can be written as:

$$
\ln \gamma_{2}=\ln \frac{X_{2}^{i}}{X_{2}}=\left(\delta_{1}-\delta_{2}\right)^{2} \frac{V_{2} \phi_{1}^{2}}{R T}
$$

Consequently the squared difference of the solubility parameters can be expressed as:

$$
\frac{\ln \left(X_{2}^{i} / X_{2}\right)}{V_{2} \phi_{1}^{2} /(R T)}=\left(\delta_{1}-\delta_{2}\right)^{2} \text {. }
$$

In terms of Hansen parameters, the simple univariate quadratic polynomial of Eq. (13) can be extended to a trivariate polynomial, 


$$
\frac{\ln \left(X_{2}^{i} / X_{2}\right)}{V_{2} \phi_{1}^{2} /(R T)}=D_{0}+D_{1}\left(\delta_{1 d}-\delta_{2 d}\right)^{2}+D_{2}\left(\delta_{1 p}-\delta_{2 p}\right)^{2}+D_{3}\left(\delta_{1 h}-\delta_{2 h}\right)^{2}
$$

which can also be written as [38]

$$
\ln X_{2}=D_{0}^{\prime}+D_{1}^{\prime}\left(\delta_{1 d}-\delta_{2 d}\right)^{2}+D_{2}^{\prime}\left(\delta_{1 p}-\delta_{2 p}\right)^{2}+D_{3}^{\prime}\left(\delta_{1 h}-\delta_{2 h}\right)^{2}
$$

with $D_{0}, D_{1}, D_{2}, D_{3}$ and ${D^{\prime}}_{0}, D^{\prime}{ }_{1}, D^{\prime}{ }_{2}, D^{\prime}{ }_{3}$ being constants.

As is evident from Eq. (14) and Eq. (15), also the solubility parameter approach can be considered as a linear combination of terms attributed to different types of intermolecular interactions, similar to the Abraham LFER model. However, in this case the descriptors $\left(\delta_{1 x}-\delta_{2 x}\right)$ do not represent the solute properties as such but the differences between solvent and solute properties. Whilst in the Abraham LFER approach the solvent specific constants include both, the solvent properties and a scaling factor to fit the predicted quantity, the constants $D$ and $D^{\prime}$ in Eq. (14) and Eq. (15) are mere scaling factors, correlating each pair (squared difference) of solvent and solute parameter to the physicochemical target property $\left(\ln X_{2}\right)$. As the solubility parameter approach separates the scaling factors from the solvent parameters, it may better allow for comparing the response for different solvents. As the description of the predicted property is not centred to a particular solvent, it facilitates the graphical depiction of the relationships between solvents and solutes in a diagram with an absolute origin which is not determined by the applied solvent.

Irrespective of these advantages, the classical Hansen model has one major drawback. The systems of Hildebrand and Hansen solubility parameters are based on the "similarity matching" rule "like dissolves like". However, it should be considered that particularly in case of acidic and basic components (or also in case of Lewis acids and bases) "complementary matching" can be the dominating principle. In order to quantify electron-donor and acceptor properties, Beerbower et al. developed a four parameter system in which $\delta_{\mathrm{h}}$ is substituted by an acidic $\left(\delta_{\mathrm{a}}\right)$ and a basic $\left(\delta_{\mathrm{b}}\right)$ solubility parameter $\left(\delta_{\mathrm{h}}{ }^{2}=2 \delta_{\mathrm{a}} \delta_{\mathrm{b}}\right)$ [39]. This subdivision of the hydrogen-bonding parameter into an acidity and a basicity component has its analogue in the overall solute hydrogen bond acidity and basicity descriptors in LFER. Unfortunately, in contrast to $\mathrm{HSBs}$, only very limited sources of $\delta_{a}$ and $\delta_{b}$ values are available in literature and a group contribution method does not exist. For this reason, this study was based on three-component Hansen parameters in their non-expanded form.

A main goal of this work was to study the applicability of the HSP method to analyze the behaviour of different compounds in Cerasome LEKC. It is scrutinized whether the Hansen approach is able to elucidate further relationships remaining latent with the Abraham model and whether it can thus support or complement the Abraham approach. Furthermore, the applicability of HSPs to predict the distribution of compounds in other model systems and the permeation through human skin are addressed.

\section{Materials and methods}

Data sets used in this study

All following considerations regarding the interpretation of LEKC retention factors are based on a comprehensive dataset created by Zhang, K. et al. [11], which comprises experimentally determined log $k_{7.4}$ values of 70 compounds (Tab. 1, see Appendix). For comparison with skin penetration data, another set of 168 substances was compiled from 6 different sources (Tab. 2, see Appendix). Hansen solubility parameters were taken from literature if available. In all other cases, where experimentally determined values could 
not be found, HSPs were calculated using the group contribution method of Hoftyzer and van Krevelen [40]. Octanol-water distribution coefficients $\left(\log D_{7.4}\right)$ were compiled from six sources. If not available from literature they were calculated either with $A C D /$ PhysChem Suite (ACD/Labs) or with the Property viewer of ChemAxon chemicalize.org, both accessible via the chemical database ChemSpider (Royal Society of Chemistry, London, UK) (www.chemspider.com).

\section{Intepolation method for prediction of LEKC retention factors and of human skin permeability coefficients}

In this study the k-nearest neighbor method was used for prediction of LEKC retention factors and of human skin permeability data. The k-nearest neighbor method is a non-parametric, local, and deterministic spatial interpolation technique which predicts the unknown value of a data point as the average value of its $k$ nearest neighbor points. The calculation of the algorithm was performed using Microsoft Excel. First the Euclidean distance between the unknown and each known data point is calculated. Then for the two ( $k=2$ in case of LEK retention factors) or three ( $k=3$ in case of skin permeability coefficients) least distant known data points the retention factors or the skin permeability coefficients were looked up and averaged.

\section{Results and Discussions}

All calculations and considerations made in this study are based on the two sets of data mentioned in the materials and methods section. One of them comprises in-vitro data measured with Cerasome LEKC, the other encompasses human skin penetration data compiled from different sources of literature. To every compound of each dataset a three-component HSP was assigned, describing its interaction properties with respect to dispersive, polar, and hydrogen bonding forces. If available from literature, experimentally determined HSP values were used. In all other cases HSPs were calculated by a group contribution method. HSPs are always subject to a certain level of uncertainty, which is lower in case of experimentally created data. HSPs obtained by group contribution are described to have an accuracy of approximately $10 \%$ [41]. Visualization of LEKC retention factors or stratum corneum permeabilities in dependence of HSPs requires plotting a dependent variable versus three independent variables $\left(\delta_{d}, \delta_{p}, \delta_{h}\right)$. As these four-dimensional datasets cannot be visualized in plane diagrams, different methods have been developed in the past to solve this problem by means of data reduction. One approach is to merge two partial solubility parameters by pythagorian addition, for example $\delta_{d}$ and $\delta_{p}$, as realized in Bagley diagrams [35]. Another approach, known as Teas plot, is the presentation of fractional solubility parameters (e.g. $\left.\delta_{d} /\left(\delta_{d}+\delta_{p}+\delta_{h}\right)\right)$ in a three component diagram. All these methods have in common a loss of information thus distorting the results [42]. For this reason, three dimensional diagrams (often called Hansen space) were chosen here to depict the retention or permeation properties of the tested substances in correlation to HSPs.

\section{Description of Cerasome LEKC retention factors in terms of HSPS}

Fig. 1 shows the data points of all compounds tested in LEKC experiments within the Hansen space. The retention factors are represented by different shapes of the markers. In contrast to Hansen's basic concept, where all good solvents are clustered within one single solubility sphere, no such single-centered area covering the data points of all compounds with large retention factors can be found in this diagram. Instead not only one but two focal areas are formed by strongly retained substances which are separated by a broad region with data points of better eluting compounds. One of these clusters can be found in the region of $\delta_{d}=15$ to $18 \mathrm{MPa}^{1 / 2}, \delta_{p}=0$ to $4 \mathrm{MPa}^{1 / 2}$ and a second cluster is seen between $\delta_{d}=19$ to $21 \mathrm{MPa}^{1 / 2}$, 
$\delta_{p}=3$ to $8 \mathrm{MPa}^{1 / 2}$. Such a pattern of more than one area of high solubility is described to be typical for surfactants and copolymers $[43,44]$. It is characteristic for molecules in which sites with different interactive properties are spatially separated from one another or where such sites of a number of molecules cluster together. By contrast, mixtures of different types of small molecules without any ordered supramolecular structure do not show multi-centered pattern of solubility in HSP diagrams. Instead, they reveal a single solubility maximum whose coordinates can be calculated as the volume-fraction-weighted average of the components' HSPs. Hence, the complex pattern of LEKC retention factors within the Hansen space indicates interactions either with amphiphilic molecules or with ordered structures. Looking at the components of Cerasome 9005, this product represents a mixture of a variety of amphiphilic compounds. In view of its liposomal nature it must be assumed that most of the components are regularly arranged, thus forming extended hydrophilic and hydrophobic regions. It is difficult to derive experimentally determined HSP values for lecithin, ceramides, cholesterol and fatty acids from literature. Only for the last two mentioned substances tabular values could be found. HSPs for dipalmitoylphosphatidylcholine (DPPC) and N-stearoyl sphingosine (as typical members of the lecithin- and ceramide group) were calculated using the method of Hoftyzer and van Krevelen [40]. Fig. 1 shows the HSP coordinate positions of the Cerasome components together with the test samples of the LEKC experiments. Interestingly, compounds with high $k_{7.4}$ values are mainly clustered around the data points of the Cerasome lipids, indicating mutual interactions. The solubility parameters of lecithin, ceramides and fatty acids are relatively close to each other with $\delta_{d}$ being in the range of 16.3 to $16.8 \mathrm{MPa}^{1 / 2}, \delta_{p}$ ranging from 1.3 to $2.8 \mathrm{MPa}^{1 / 2}$, and $\delta_{h}$ between 5.6 and $8.5 \mathrm{MPa}^{1 / 2}$. As can be seen by comparison with hexadecane $\left(\delta_{d}=16.3 \mathrm{MPa}^{1 / 2}, \delta_{p}=0 \mathrm{MPa}^{1 / 2}, \delta_{h}=0 \mathrm{MPa}^{1 / 2}\right)$ and octadecane $\left(\delta_{d}=16.4 \mathrm{MPa}^{1 / 2}, \delta_{p}=0 \mathrm{MPa}^{1 / 2}, \delta_{h}=0 \mathrm{MPa}^{1 / 2}\right), \delta_{d}$ is mainly determined by the aliphatic chains of the lipids. From homologue series of hydrocarbons it can be deduced that longer chains result in higher $\delta_{d}$ values. However, values of $20 \mathrm{MPa}^{1 / 2}$ and above cannot be explained by aliphatic carbon chains. As solubility parameters represent the cohesion energy per molar volume, such high dispersion parameters are characteristic for compactly structured polycyclic hydrocarbons like cholestane. For this reason, $\delta_{d}$ of cholesterol (20.4 $\mathrm{MPa}^{1 / 2}$ ) [45] is incomparably higher than the value of the other, non-cyclic lipids. Due to the amphiphilic character of cholesterol, enabling hydrogen bonding as well as van der Waals binding to low polar compounds, it can be assumed that $\delta_{p}$ and $\delta_{h}$ parameters of substances with affinity to cholesterol are ranging over a wide scale. Indeed, the cluster of strongly retained compounds around the data point of cholesterol shows a large extension both in $\delta_{p}$ and $\delta_{h}$ direction. In summary, strongly retained compounds form two clusters in the Hansen space, one caused by the affinity to cholesterol and the other by binding to lecithin, ceramides and fatty acids. Both clusters are divided from each other by a region comprising the data points of substances with low $k_{7.4}$ values. As discussed before, the occurrence of two separate solubility regions, which is typically not observed with mixtures of miscible substances, raises the suspicion that in the Cerasome liposomes cholesterol is not molecularly dispersed within the other lipids but in some way separated. Indeed, it is reported that ternary mixtures of 1-palmitoyl-2-oleoyl-sn-glycero3-phosphocholine, ceramide (18:0) and cholesterol with fractions of 50\% ceramide and $25 \%$ cholesterol, resembling the ratio in stratum corneum lipids, reveal a separate phase of cholesterol monohydrate crystals besides a bilayer phase containing all three components [46]. Also in lipid membranes separated sphingolipid-rich and cholesterol-rich ordered lipid domains are believed to exist [47]. 

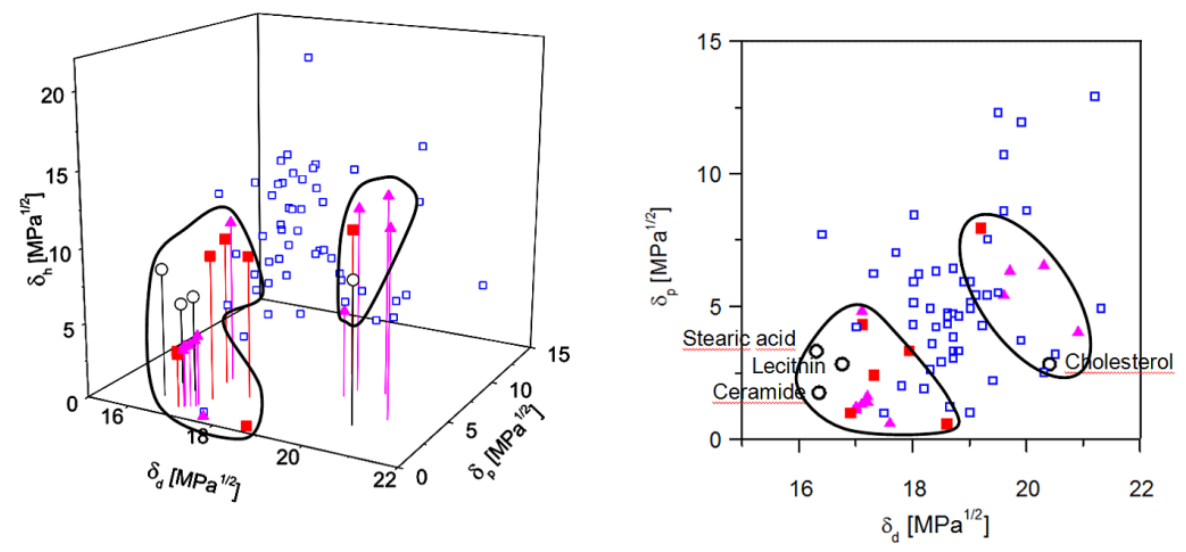

Figure 1. LEKC retention factors of the compounds tested for retention in Cerasome LEKC: Data locations of 70 tested substances in the Hansen space (perspective view and $\delta_{d} / \delta_{p}$-view). Solid squares (with drop lines): $\log k_{7.4}>0$, solid triangles (with drop lines): $\log k_{7.4}: 0$ to -0.75 , open squares: $\log k_{7.4}<-0.75$, open circles: components of Cerasome 9005.

As was shown in a former work of the author, the contours of such irregularly shaped solubility regions are determined by the plurality of different molecular fragments of a large polymer molecule, which applies also to a supramolecular structure [42]. By contrast, small molecular compounds and also their mixtures are characterized by a single centred solubility sphere. In the latter case, according to Hansen, the solubility of a substance in another can be estimated from the relative energy difference (RED). The RED is calculated from the Euclidean distance in the three-dimensional Hansen space between the data point of one substance and the centre of the other substance's solubility sphere and is defined as the ratio of this distance and the sphere's interaction radius $R$.

$$
R E D=\left[4 \cdot\left(\delta_{d}^{p}-\delta_{d}^{c}\right)^{2}+\left(\delta_{p}^{p}-\delta_{p}^{c}\right)^{2}+\left(\delta_{h}^{p}-\delta_{h}^{c}\right)^{2}\right]^{0.5} / R
$$

A RED lower than 1 indicates high solubility (coordinate position within the sphere), a RED higher than 1 characterizes substances with low solubility (coordinate position outside the sphere). However, in case of Cerasome the complex-shaped and even divided solubility region makes the classical Hansen approach inapplicable.

As it is nearly impossible to describe such irregular shapes by a single formula, it likewise renders difficult to find a simple mathematical correlation which is able to predict the solubility, or in this case the LEKC retention factor, from HSPs. For this reason, it is more expedient to use the full data set of known log $k_{7.4}$ values for prediction instead of reducing it to an approximation formula with loss of valuable information. However, because of the irregular shape of the solubility region in the Hansen space there is no predictable influence of more distant data points, so that only a local approximation is reasonable. The necessary basis for this method is a training set of a sufficient number of homogenously scattered data points without major gaps in between. The simplest way of prediction is by using a k-nearest neighbour algorithm, assigning the value of an object to the average value of its $k$ nearest neighbors. As the dataset in Tab. 1 unfortunately exhibits poorly covered regions with large distances to the closest data points, the k-nearest neighbor method can only be applied in a limited way, i.e. excluding the prediction of points which are too far from any point of the training set. In order to test the method without separate sets of training and sample data being available, $\log k_{7.4}$ of each compound in the list was predicted by using the data of all other compounds except the respective one as a trainings set. With $k=2$ it could be shown that the method works with high accuracy for all data for which the distance to the nearest point of the training 
set is smaller than $1 \mathrm{MPa}^{1 / 2}$ (average deviation of $\log k_{7.4}: 0.20$ ) (Fig. 2). However, as can be seen by some outliers, in rare cases, where a data point has to be extrapolated in a region with steeply increasing response values, mispredictions cannot entirely be prevented. Nevertheless, if a sufficiently large, dense and evenly distributed training dataset is available it can be expected that this model-independent method allows even more accurate predictions. As HSPs can be easily calculated by simple group contribution methods, the presented approach allows the prediction of interactions of any organic substances with stratum corneum lipids directly from the molecular structure without the need of sophisticated computer programs. Surprisingly, Fig. 2 shows that neutral, anionic and cationic compounds are fitted equally well by the same regression line. Hence, this example does not identify any necessity to consider charged compounds in a special way.

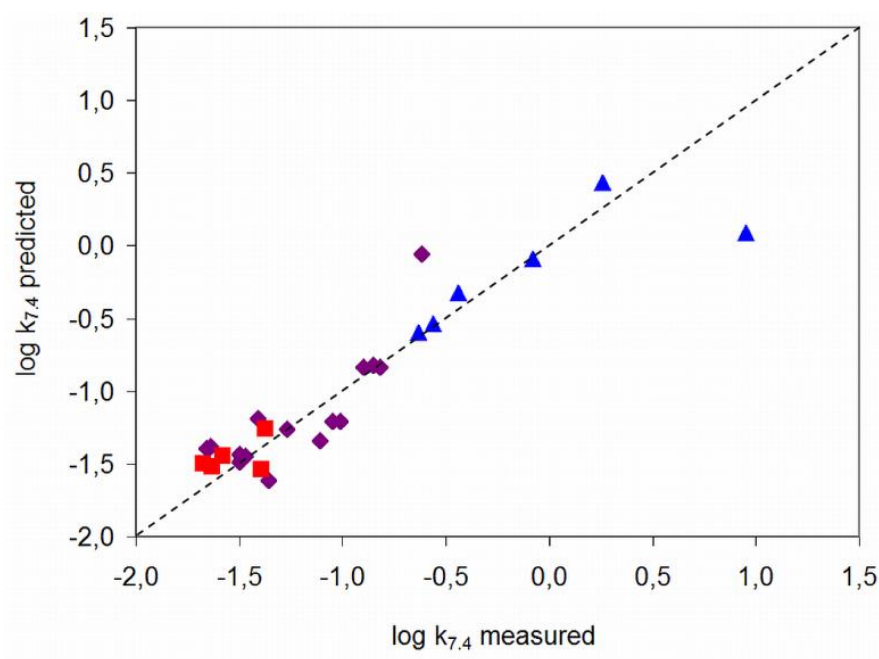

Figure 2. LEKC retention factors ( $\log k_{7.4}$ ) predicted from HSPs (nearest neighbourhood method) vs. measured log $k_{7.4^{-}}$ values (Compounds with HSP data points more distant than $1 \mathrm{MPa}^{1 / 2}$ to the nearest point of the model's trainings set were excluded from prediction for lack of accuracy). Squares: acids, diamonds: neutral compounds, triangles: bases.

LFER analysis as described by Zhang et al., however, considers the charge state of the tested compounds [11]. By regressing Eq. (3) on the dataset of Table 1, they developed the following formula for $k_{7.4}$ : $\log k_{7.4}=-1.844-0.587 S-1.427 B+1.782 V+0.164 J^{+}+1.912 J^{-}$

Fig. 3. shows the values predicted by this linear relationship equation for the same compounds as in Fig. 2. Comparison of both diagrams reveals very similar results of both methods $\left(R_{\text {HSP }}^{2}=0.86, R_{\text {LFER }}^{2}=0.90\right.$; Slope of the linear trendline: HSP: 0.84, LFER: 0.90). However it should not be overlooked that the HSP method needs a more evenly distributed training dataset (or a better interpolation algorithm) in order to predict the whole range of sample compounds with sufficient accuracy. 


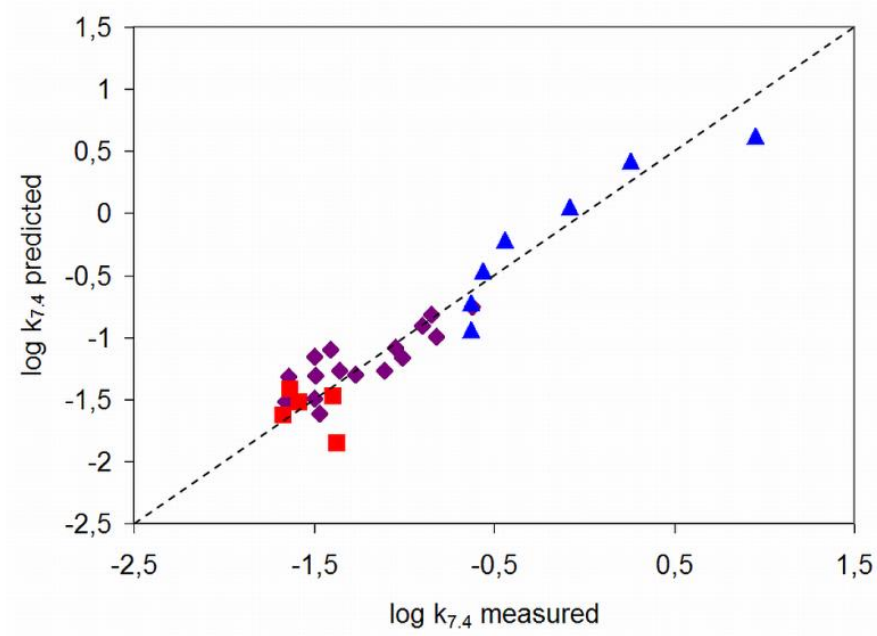

Figure 3. LEKC retention factors ( $\left.\log k_{7.4}\right)$ of the same subset of compounds as in Fig. 2 predicted with LFER. Squares: acids, diamonds: neutral compounds, triangles: bases.

\section{Description of octanol-water distribution coefficients in terms of HSPS}

Another more commonly used in-vitro-parameter which was also often applied for the prediction of skin permeability is the octanol-water partition coefficient $P$ or, if all dissociation species at $\mathrm{pH} 7.4$ are considered, the octanol-water distribution coefficient $D_{7.4}$. However, compared to log $k_{7.4}$, a different picture emerges if $\log D_{7.4}$ is displayed in the Hansen diagram (Fig. 4). Data points representing high $\log D_{7.4}$ values form a widespread cloud. The HSP of octanol does not represent the center of this cluster, as one might expect from Hansen theory. It has to be considered that, as $\log D_{7.4}$ does not describe the solubility in octanol but the distribution between octanol and water, this parameter is also a function of the compounds' aqueous solubility.

The center of the solubility sphere of water is reported $\delta_{d}=15.1 \mathrm{MPa}^{1 / 2}, \delta_{p}=20.4 \mathrm{MPa}^{1 / 2}$, $\delta_{h}=16.5 \mathrm{MPa}^{1 / 2}$ and the sphere's interaction radius is given as $18.1 \mathrm{MPa}^{1 / 2}$ (based on the assumption of "good" solutes being soluble to more than $1 \%$ in water) [48]. If the relative energy difference RED of the neutral components is plotted against the octanol-water partition coefficient, a RED value of 1 can be correlated with a $\log D_{7.4}$ of about 2 (data not shown), which means that compounds with HSPs located outside the $1 \%$-water-solubility sphere are distributed less than $1 \%$ within the water-and more than $99 \%$ within the octanol-phase. The same is also valid if the RED of acidic and basic compounds is plotted against $\log P$, indicating that the neutral species of acids and bases partition in the same manner as nondissociating compounds. Thus, it can be stated that $\log D_{7.4}$ and $\log P$ are substantially governed by the aqueous solubility of the compounds. This is in agreement to the known fact that for similar classes of compounds, excellent linear relationships exist between aqueous solubility $c_{w}$ and $\log P$, as described by

$\log P=a \log \left(\frac{1}{c_{w}}\right)+b$

with $a$ and $b$ being constants $[49,50]$.

It follows that Cerasome retention factors provide a more differentiated model for partitioning of drugs into stratum corneum lipids than the octanol-water distribution coefficient. 

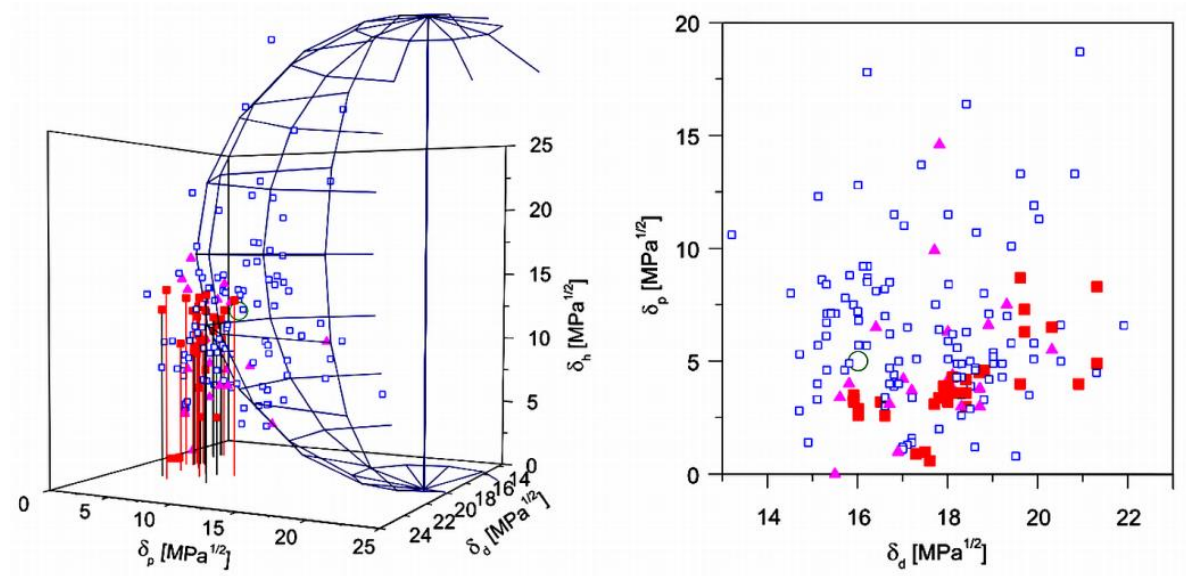

Figure 4. Octanol-water distribution coefficients $\left(\log D_{7.4}\right)$ of compounds tested for human stratum corneum penetration: Data locations of 168 tested substances in the Hansen space (perspective view and $\delta_{d} / \delta_{p}$-view). Solid squares (with drop lines in the perspective view): $\log D_{7.4}>2.5$, solid triangles: $\log D_{7.4}: 2.5$ to 2 , open squares:

$\log D_{7.4}<2$, open circle: octanol. The perspective view shows also the solubility sphere of water.

\section{Description of human skin permeability coefficients in terms of HSPs}

Though Cerasome was developed to largely mimic the lipid composition in the stratum corneum, conditions in real skin are somewhat different from those in liposome dispersions. The differences do not only concern the structural arrangement of the lipid layers but also their composition. As mentioned above, Cerasome contains lecithin which is not a component of the stratum corneum lipids. Nevertheless, compared to other in-vitro test systems for skin permeation, the Cerasome dispersion exhibits one of the closest analogies to human skin. Using a database with human skin permeability coefficients $\left(k_{p}\right)$ of 168 different compounds, the correlation with LEKC retention factors was analyzed. The permeability coefficients were compiled from different literature sources and averaged (Tab. 2). Fig. 5 shows the HSPs of the analyzed compounds as a graphical representation in the Hansen space with the permeability coefficients classified as different markers.
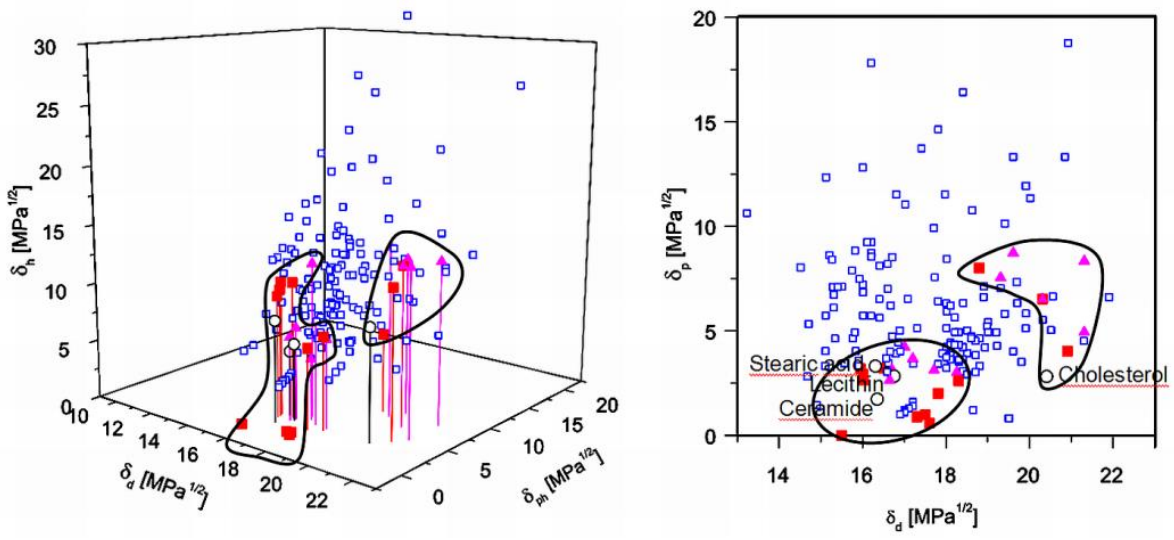

Figure 5. Human skin permeability coefficients $\left(\log k_{\mathrm{p}}\right)$ of compounds tested for human stratum corneum penetration: Data locations of 141 tested substances in the Hansen space (perspective view and $\delta_{d} / \delta_{p}$-view). Solid squares (with drop lines): $\log k_{\mathrm{p}}>-1.2$, solid triangles (with drop lines): $\log k_{\mathrm{p}}:-1.2$ to 1.32 , open squares: $\log k_{\mathrm{p}}<-1.32$, open circles: components of stratum corneum lipids and the lecithin component DPPC.

Compared to the LEKC data set, the compounds chosen for skin permeability analysis are spread over a more extended HSP range particularly towards lower $\delta_{d}$ and higher $\delta_{p}$ values. However, the distribution pattern of $k_{p}$ is largely the same as that of $k_{7.4}$ in case of LEKC data. Again, there is one cluster of high $k_{p}$ 
values in the region of ceramides and fatty acids and another around the HSP of cholesterol. Also in this case, the k-nearest neighbor method is able to predict the $k_{p}$ values from the HSPs of the compounds. Fig. 6 shows the correlation between predicted and measured $k_{p}$ values. As done before with $k_{7.4}$ values, each value of the data set in Tab. 2 was predicted on the basis of all other data, which were used as the training set. The predicted value was assigned to the average value of the three nearest neighbor points of the training set. Because of the large size of the data set on which the method is based, the number of predictable data points did not have to be restricted. The average deviation of log $k_{p}$ was 0.51 . Though most of the data points are located along the $45^{\circ}$ line through the origin, the slope of the regression line (0.6) deviates from $1\left(R^{2}=0.62\right)$. This is mainly due to an underestimation of log $k_{p}$ values smaller than -4 . The majority of these substances are high molecular weight compounds. As detailed below, for those compounds the low diffusion coefficient can be a biasing factor in prediction of $k_{p}$. However, for most substances of a medium range molecular weight, this example demonstrates the performance of the method. The accuracy might be additionally increased by the application of a more sophisticated interpolation algorithm, like the modified Shepards method described by Renka [42,51,52], which, however, was not part of this work.

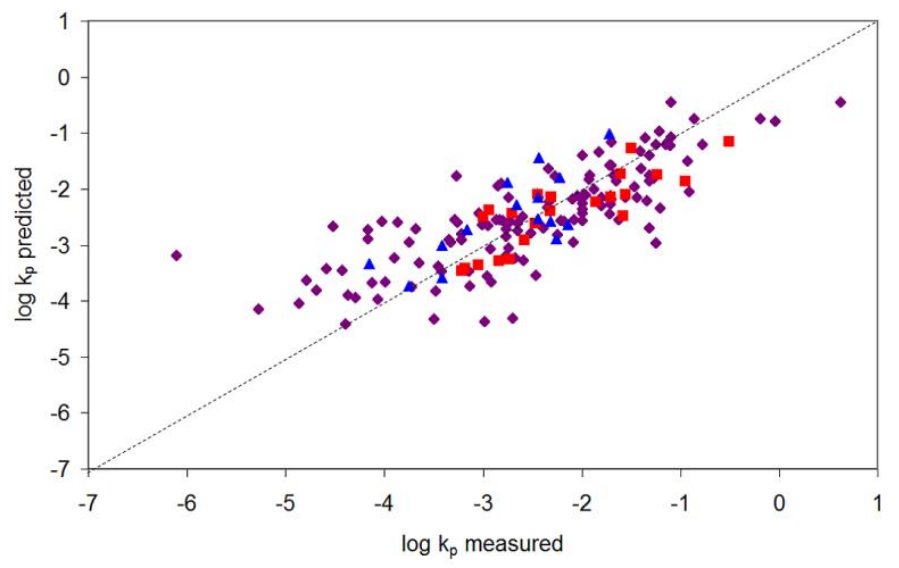

Figure 6: Human skin permeability coefficients ( $\log k_{p}$ ) predicted from HSPs (nearest neighbourhood method) vs. measured log $k_{p}$-values. Squares: acids, diamonds: neutral compounds, triangles: bases.

This data analyses demonstrate that LEKC retention factors as well as human skin permeability coefficients are predictable from Hansen solubility parameters. They show that compounds which are highly retained in LEKC and those which are well permeable through human skin have similar HSPs and thus comparable distribution patterns in the Hansen space. This congruence is somewhat surprising as it is known, that skin permeability is not only governed by the water/stratum corneum partitioning but also by diffusion within the stratum corneum. Hence, $k_{p}$ depends on both the water skin partition coefficient $k_{s c}$ and the diffusion coefficient in the stratum corneum $D_{s c}$, as described by the following equation,

$$
\log k_{p}=\log k_{s c}+\log \frac{D_{s c}}{h}
$$

in which $h$ is the thickness of the stratum corneum [53]. As $k_{7.4}$ quantifies a partitioning process into a lipid system similarly composed as the stratum corneum it is supposed to be a good estimate for $k_{s c}\left[53\right.$ ]. $D_{s c}$ was reported to be a function of the molecular volume $V_{m}$,

$$
D_{s c}=D_{s c}^{0} \exp \left(-b V_{m}\right)
$$


with $D^{o}{ }_{s c}$ being the diffusivity of a molecule with a vanishing small $V_{m}$ and $b$ a constant which is inversely proportional to the average free volume available for diffusion [6]. From Eq. (20) a proportionality between $\log D_{s c}$ and $-V_{m}$ can be deduced. It may therefore be concluded that log $k_{p}$ should be linearly related not only to $\log k_{7.4}$ but also to $-V_{m}$. However, as follows from the very similar distribution pattern of LEKC retention and skin permeation in the Hansen space, the latter seems to be mainly governed by stratum corneum lipid partitioning and, for a wide range of substances, to be determined only to a minor degree by diffusion properties.

\section{Conclusions}

Summarizing these data, the distribution of substances into Cerasome liposomes is primarily governed by specific affinities to the four main components of this system with the different solubility behaviour of cholesterol playing a special role. By contrast, the octanol-water distribution was found to be largely determined by a more unspecific displacement of hydrophobic compounds from the aqueous phase. The affinity of different compounds to Cerasome can be portrayed using Hansen solubility parameters. As Cerasome resembles the stratum corneum lipids not only with respect to their composition but also concerning their lamellar arrangement, it constitutes an excellent in-vitro test system for skin partition. The high similarity to stratum corneum lipids is also expressed in a largely similar pattern of $k_{7.4}$ and $k_{p}$ intensity distributions in the Hansen space. In both systems a main reason for the complex relationship between skin permeability or LEKC retention on the one hand and the different kinds of interactive forces on the other are the different solubility effects of cholesterol and the other lipids.

\section{References}

[1] N. Dayan, Cosmetics \& Toiletries 120 (2005) 67-76.

[2] M. Nino, G. Calabrò, P. Santoianni, Dermatology Online Journal 16 (2010).

[3] J.J. Berti, J.J. Lipsky, Mayo Clinic Proceedings 70 (1995) 581-586.

[4] Y.G. Anissimov, O.G. Jepps, Y. Dancik, M.S. Roberts, Advanced Drug Delivery Reviews 65 (2013) 169190.

[5] K.B. Sloan, S.A.M. Koch, K.G. Siver, F.P. Flowers, Journal of Investigative Dermatology 87 (1986) 244252.

[6] R.O. Potts, R.H. Guy, Pharmaceutical Research 9 (1992) 663-669.

[7] J.J. Martínez-Pla, Y. Martín-Biosca, S. Sagrado, R.M. Villanueva-Camañas, M.J. Medina-Hernández, Biomedical Chromatography 17 (2003) 530-537.

[8] C.Y. Yang, S.J. Cai, H. Liu, C. Pidgeon, Advanced Drug Delivery Reviews 23 (1997) 229-256.

[9] Y.J. Wang, J. Sun, H.Z. Liu, J.F. Liu, L.Q. Zhang, K. Liu, Z.G. He, Analyst 134 (2009) 267-272.

[10] D.L. Xian, K.L. Huang, S.Q. Liu, J.Y. Xiao, Chinese Journal of Chemistry 26 (2008) 671-676.

[11] K. Zhang, M. Chen, G.K.E. Scriba, M.H. Abraham, A. Fahr, X. Liu, Journal of Pharmaceutical Sciences 100 (2011) 3105-3113.

[12] N.Y. Schürer, in Handbook of Atopic Eczema, J. Ring, B. Przybilla, T. Ruzicka, Eds., Springer Verlag, Berlin, Germany, 2006, p. 157.

[13] N.Y. Schurer, P.M. Elias, Advances in lipid research 24 (1991) 27-56.

[14] N.Y. Schürer, G. Plewig, P.M. Elias, Dermatologica 183 (1991) 77-94.

[15] L. Coderch, O. López, A. de la Maza, J.L. Parra, American Journal of Clinical Dermatology 4 (2003) 107-129.

[16] R.E. Baynes, X.R. Xia, V. Vijay, J.E. Riviere, SAR and QSAR in Environmental Research 19 (2008) 615630.

[17] J. Hildebrand, R.L. Scott, The Solubility of Nonelectrolytes, third ed., Reinhold, New York, NY, 1950. 
[18] C.M. Hansen, Hansen Solubility Parameters: A User's Handbook, CRC, Boca Raton, FL, 1999.

[19] S.H. Neau, G.L. Flynn, S.H. Yalkowsky, International Journal of Pharmaceutics 49 (1989) $223-229$

[20] A. Amin, M. Dare, A. Sangamwar, A.K. Bansal, Pharmaceutical Development and Technology 17 (2012) 614-624.

[21] C. Bordes, V. Fréville, E. Ruffin, P. Marote, J.Y. Gauvrit, S. Briançon, P. Lantéri, International Journal of Pharmaceutics 383 (2010) 236-243.

[22] A. Forster, J. Hempenstall, I. Tucker, T. Rades, International Journal of Pharmaceutics 226 (2001) 147-161.

[23] A.N. Ghebremeskel, C. Vemavarapu, M. Lodaya, International Journal of Pharmaceutics 328 (2007) 119-129.

[24] D.J. Greenhalgh, A.C. Williams, P. Timmins, P. York, Journal of Pharmaceutical Sciences 88 (1999) 1182-1190.

[25] B.C. Hancock, P. York, R.C. Rowe, International Journal of Pharmaceutics 148 (1997) 1-21.

[26] D. Jain, K. Pathak, AAPS PharmSciTech 11 (2010) 133-142.

[27] K. Kuksal, K. Pathak, Indian Journal of Pharmaceutical Sciences 70 (2008) 609-613.

[28] M.A. Mohammad, A. Alhalaweh, S.P. Velaga, International Journal of Pharmaceutics 407 (2011) 6371.

[29] M. Shah, Y. Agrawal, Pharmaceutical Development and Technology 18 (2013) 582-590

[30] K. Vay, S. Scheler, W. Friess, International Journal of Pharmaceutics 416 (2011) 202-209.

[31] P. Bustamante, J. Navarro-Lupión, M.A. Peña, B. Escalera, International Journal of Pharmaceutics 414 (2011) 125-130.

[32] J. Breitkreutz, Pharmaceutical Research 15 (1998) 1370-1375.

[33] L.G. Martini, P. Avontuur, A. George, R.J. Willson, P.J. Crowley, European Journal of Pharmaceutics and Biopharmaceutics 48 (1999) 259-263.

[34] S. Abbott, International Journal of Cosmetic Science 34 (2012) 217-222.

[35] R. Gröning, F.J. Braun, Pharmazie 51 (1996) 337-341.

[36] T. Hashiguchi, T. Yasutake, T. Manako, M. Otagiri, International Journal of Pharmaceutics 158 (1997) 11-18.

[37] E. Squillante, T. Needham, H. Zia, International Journal of Pharmaceutics 159 (1997) 171-180.

[38] P. Bustamante, B. Escalera, A. Martin, E. Selles, Journal of Pharmacy and Pharmacology 45 (1993) 253-257.

[39] A. Beerbower, P.L. Wu, A. Martin, Journal of Pharmaceutical Sciences 73 (1984) 179-188.

[40] D.W. van Krevelen, Properties of Polymers, Elsevier, Amsterdam, Netherlands, p. 189.

[41] A. Jonquières, D., Roizard, J. Cuny, P. Lochon, Journal of Membrane Science 121 (1996) 117-133.

[42] S. Scheler, Journal of Applied Polymer Science 105 (2007) 3121-3131.

[43] C.M. Hansen, in Hansen Solubility Parameters: A User's Handbook, C.M. Hansen, Ed., CRC, Boca Raton, FL, 2007, p. 332.

[44] A.F.M. Barton, CRC Handbook of solubility parameters and other cohesion parameters, CRC, Boca Raton, FL, 1991, p. 426.

[45] C.M. Hansen, T.S. Poulsen, in Hansen Solubility Parameters: A User's Handbook, C.M. Hansen, Ed., CRC, Boca Raton, FL., 2007, p. 275.

[46] M.R. Ali, K.H. Cheng, J. Huang, Biochemistry 45 (2006) 12629-12638.

[47] M. London, E. London, Journal of Biological Chemistry 279 (2004) 9997-10004.

[48] C.M. Hansen, in Hansen Solubility Parameters: A User's Handbook, C.M. Hansen, Ed., CRC, Boca Raton, FL, 2007, p. 21.

[49] M. Coates, D.W. Connell, D.M. Barron, Environmental Science \& Technology 19 (1985) 628-632.

[50] S.C. Valvani, S.H. Yalkowsky, T.J. Roseman, Journal of Pharmaceutical Sciences 70 (1981) 502-507. 
[51] D. Douroumis, S. Scheler, A. Fahr, Journal of Pharmaceutical Sciences 97 (2008) 907-918.

[52] R.J. Renka, ACM Transactions on Mathematical Software 14 (1988) 139-148.

[53] K. Zhang, M. Chen, G.K.E. Scriba, M.H. Abraham, A. Fahr, X. Liu, Journal of Pharmaceutical Sciences 101 (2012) 2034-2044.

[54] O.A. Santos-Filho, A.J. Hopfinger, T. Zheng, Molecular Pharmaceutics 1 (2004) 466-476.

[55] A. Wilschut, W.F. ten Berge, P.J. Robinson, T.E. McKone, Chemosphere 30 (1995) 1275-1296.

[56] C. Hansch, A. Leo, Substituent constants for correlation analysis in chemistry and biology, Wiley, New York, NY, 1979.

[57] G.L. Flynn, in Principles of route-to-route extrapolation for risk assessment, T.R. Gerrity, C.J. Henry, Eds., Elsevier, New York, 1990, p. 93.

[58] M.D. Barratt, Toxicology in Vitro 9 (1995) 27-37.

[59] M.E. Johnson, D. Blankschtein, R. Langer, Journal of Pharmaceutical Sciences 86 (1997) 1162-1172.

[60] W.J. Pugh, I.T. Degim, J. Hadgraft, International Journal of Pharmaceutics 197 (2000) 203-211.

[61] C. Hansch, A. Leo, D. Hoekman, Exploring QSAR: Hydrophobic, Electronic, and Steric Constants, American Chemical Society, Washington DC, 1995, USA, p. 183.

[62] J.L. Dwan `Isa, M. Dinguizli, V. Preat, A. Arien, M. Brewster, Journal of Controlled Release 101 (2005) 366-368.

[63] P. Bustamante, M.A. Peña, J. Barra, Journal of Pharmacy and Pharmacology 50 (1998) 975-982.

[64] M.A. Peña, Y. Daali, J. Barra, P. Bustamante, Chemical \& Pharmaceutical Bulletin 48 (2000) 179-183. 


\section{Appendix}

Table 1. LEKC retention factors ( $\left.\log k_{7.4}\right)$, octanol-water partition and distribution coefficients at $\mathrm{pH} 7.4(\log P$ and $\left.\log D_{7.4}\right)$, LFER solute descriptors, and Hansen solubility parameters $\left(\delta_{d}, \delta_{p}, \delta_{h}\right)$ of 70 substances tested with Cerasome electrokinetic chromatography [11] (Zhang et al., 2011). One substance of the original dataset was omitted, because the HSP of iodinated compounds cannot be calculated by current group contribution methods.

\begin{tabular}{|c|c|c|c|c|c|c|c|c|c|c|c|c|c|c|}
\hline Compound & $\begin{array}{c}\boldsymbol{\delta}_{d} \\
\mathrm{MPa}^{1 / 2} \\
\end{array}$ & $\begin{array}{c}\boldsymbol{\delta}_{p} \\
\mathrm{MPa}^{1 / 2}\end{array}$ & $\begin{array}{c}\boldsymbol{\delta}_{\boldsymbol{h}} \\
\mathrm{MPa}^{1 / 2}\end{array}$ & $\begin{array}{c}\text { Charge } \\
\text { state }\end{array}$ & $\begin{array}{l}\text { log } \\
P_{\text {oct }}\end{array}$ & $\begin{array}{l}\log \\
D_{7.4} \\
\end{array}$ & $\begin{array}{l}\log \\
k_{7.4} \\
\end{array}$ & $E$ & $S$ & $A$ & $B$ & $\boldsymbol{v}$ & $J^{+}$ & 5 \\
\hline Cortexolone & 18.8 & 4.6 & 12.5 & neutral & 2.52 & 2.52 & -1.11 & 1.91 & 3.45 & 0.36 & 1.60 & 2.738 & 0 & 0 \\
\hline Cortexone & 18.4 & 4.2 & 9.2 & neutral & 2.88 & 2.88 & -0.82 & 1.74 & 3.50 & 0.14 & 1.31 & 2.680 & 0 & 0 \\
\hline Corticosterone & 18.6 & 4.6 & 12.4 & neutral & 1.94 & 1.94 & -1.27 & 1.86 & 3.43 & 0.40 & 1.63 & 2.738 & 0 & 0 \\
\hline Cortisone & 19.1 & 5.4 & 12.8 & neutral & 1.47 & 1.47 & -1.57 & 1.96 & 3.50 & 0.36 & 1.87 & 2.754 & 0 & 0 \\
\hline Dexamethasone & 18.6 & 4.7 & 14.7 & neutral & 1.83 & 1.83 & -1.40 & 2.04 & 3.51 & 0.71 & 1.92 & 2.913 & 0 & 0 \\
\hline Digitoxin & 18.7 & 3.0 & 14.6 & neutral & 1.86 & 1.86 & -1.12 & 3.46 & 5.56 & 1.67 & 4.35 & 5.693 & 0 & 0 \\
\hline Estriol & 18.7 & 3.8 & 16.2 & neutral & 2.54 & 2.54 & -1.37 & 1.97 & 1.74 & 1.06 & 1.63 & 2.257 & 0 & 0 \\
\hline Hydrocortisone & 19.0 & 4.9 & 15.1 & neutral & 1.55 & 1.55 & -1.47 & 2.03 & 3.49 & 0.71 & 1.90 & 2.797 & 0 & 0 \\
\hline Hydrocortisone-21-acetate & 18.6 & 4.3 & 12.6 & neutral & 2.19 & 2.19 & -1.41 & 1.89 & 2.88 & 0.46 & 2.16 & 3.095 & 0 & 0 \\
\hline 17-Hydroxyprogesterone & 18.4 & 4.2 & 9.2 & neutral & 3.17 & 3.17 & -0.90 & 1.64 & 3.35 & 0.25 & 1.31 & 2.680 & 0 & 0 \\
\hline Prednisolone & 19.0 & 5.1 & 15.3 & neutral & 1.62 & 1.62 & -1.50 & 2.21 & 3.10 & 0.71 & 1.92 & 2.754 & 0 & 0 \\
\hline Testosterone & 18.3 & 3.6 & 9.3 & neutral & 3.29 & 3.29 & -0.85 & 1.54 & 2.59 & 0.32 & 1.19 & 2.382 & 0 & 0 \\
\hline Bibenzyl & 18.6 & 0.6 & 0.0 & neutral & 4.80 & 4.80 & 0.72 & 1.22 & 1.04 & 0.00 & 0.33 & 1.606 & 0 & 0 \\
\hline 4-Chloro-2-methylphenol & 20.3 & 6.5 & 13.3 & neutral & 2.78 & 2.78 & -0.74 & 0.89 & 0.91 & 0.63 & 0.22 & 1.038 & 0 & 0 \\
\hline 4-Chloro-3,5-dimethylphenol & 20.9 & 5.7 & 12.4 & neutral & 3.27 & 3.27 & -0.51 & 0.93 & 0.96 & 0.64 & 0.21 & 1.179 & 0 & 0 \\
\hline 3,4-Dimethylphenol & 17.0 & 4.2 & 12.9 & neutral & 2.23 & 2.23 & -1.34 & 0.83 & 0.90 & 0.55 & 0.38 & 1.056 & 0 & 0 \\
\hline 1-Fluoro-2,4-dinitrobenzene & 21.2 & 12.9 & 5.1 & neutral & 1.47 & 1.47 & -1.63 & 1.01 & 1.69 & 0.00 & 0.45 & 1.082 & 0 & 0 \\
\hline 2-Naphthol & 19.7 & 6.3 & 12.3 & neutral & 2.70 & 2.70 & -0.70 & 1.52 & 1.08 & 0.61 & 0.40 & 1.144 & 0 & 0 \\
\hline Resorcinol & 18.0 & 8.4 & 21.0 & neutral & 0.80 & 0.79 & -1.49 & 0.98 & 1.11 & 1.09 & 0.52 & 0.833 & 0 & 0 \\
\hline Styrene & 17.6 & 0.6 & 0.0 & neutral & 2.95 & 2.95 & -0.62 & 0.85 & 0.65 & 0.00 & 0.16 & 0.955 & 0 & 0 \\
\hline Toluene & 17.5 & 1.0 & 0.0 & neutral & 2.73 & 2.73 & -0.83 & 0.60 & 0.52 & 0.00 & 0.14 & 0.857 & 0 & 0 \\
\hline $4-\mathrm{BrC}_{6} \mathrm{H}_{4} \mathrm{OH}$ & 21.3 & 4.9 & 13.9 & neutral & 2.59 & 2.58 & -0.87 & 1.08 & 1.17 & 0.67 & 0.20 & 0.950 & 0 & 0 \\
\hline $3-\mathrm{CH}_{3} \mathrm{C}_{6} \mathrm{H}_{4} \mathrm{OH}$ & 18.0 & 5.1 & 12.9 & neutral & 1.96 & 1.96 & -1.48 & 0.82 & 0.88 & 0.57 & 0.34 & 0.916 & 0 & 0 \\
\hline $4-\mathrm{CH}_{3} \mathrm{C}_{6} \mathrm{H}_{4} \mathrm{OH}$ & 18.3 & 4.9 & 13.9 & neutral & 1.95 & 1.95 & -1.43 & 0.82 & 0.87 & 0.57 & 0.31 & 0.916 & 0 & 0 \\
\hline $\mathrm{C}_{6} \mathrm{H}_{5} \mathrm{COCH}_{3}$ & 19.6 & 8.6 & 3.7 & neutral & 1.58 & 1.58 & -1.64 & 0.82 & 1.01 & 0.00 & 0.48 & 1.013 & 0 & 0 \\
\hline $2-\mathrm{ClC}_{6} \mathrm{H}_{4} \mathrm{NH}_{2}$ & 19.3 & 5.4 & 9.2 & neutral & 1.91 & 1.91 & -1.50 & 1.03 & 0.92 & 0.25 & 0.31 & 0.939 & 0 & 0 \\
\hline $2-\mathrm{ClC}_{6} \mathrm{H}_{4} \mathrm{NO}_{2}$ & 19.6 & 10.7 & 4.1 & neutral & 2.52 & 2.52 & -1.27 & 1.02 & 1.24 & 0.00 & 0.24 & 1.013 & 0 & 0 \\
\hline $3-\mathrm{ClC}_{6} \mathrm{H}_{4} \mathrm{OH}$ & 19.3 & 7.5 & 14.3 & neutral & 2.50 & 2.49 & -1.05 & 0.91 & 1.06 & 0.69 & 0.15 & 0.897 & 0 & 0 \\
\hline $4-\mathrm{ClC}_{6} \mathrm{H}_{4} \mathrm{OH}$ & 19.3 & 7.5 & 14.3 & neutral & 2.39 & 2.39 & -1.01 & 0.92 & 1.08 & 0.67 & 0.20 & 0.897 & 0 & 0 \\
\hline $4-\mathrm{ClC}_{6} \mathrm{H}_{4} \mathrm{CH}_{2} \mathrm{OH}$ & 18.7 & 6.4 & 13.2 & neutral & 1.96 & 1.96 & -1.36 & 0.91 & 0.96 & 0.40 & 0.50 & 1.038 & 0 & 0 \\
\hline $2-\mathrm{H}_{2} \mathrm{NC}_{6} \mathrm{H}_{4} \mathrm{Ph}$ & 19.0 & 1.0 & 7.3 & neutral & 2.84 & 2.84 & -1.06 & 1.60 & 1.48 & 0.26 & 0.41 & 1.424 & 0 & 0 \\
\hline $3-\mathrm{O}_{2} \mathrm{NC}_{6} \mathrm{H}_{4} \mathrm{OH}$ & 19.9 & 11.9 & 14.7 & neutral & 2.00 & 1.96 & -0.83 & 1.05 & 1.57 & 0.79 & 0.23 & 0.949 & 0 & 0 \\
\hline $\mathrm{PhCH}_{2} \mathrm{CN}$ & 19.5 & 12.3 & 3.8 & neutral & 1.56 & 1.56 & -1.61 & 0.75 & 1.03 & 0.00 & 0.50 & 1.012 & 0 & 0 \\
\hline $\mathrm{PhCH}_{2} \mathrm{OH}$ & 18.4 & 6.3 & 13.7 & neutral & 1.10 & 1.10 & -1.66 & 0.80 & 0.87 & 0.39 & 0.56 & 0.916 & 0 & 0 \\
\hline $\mathrm{PhNH}_{2}$ & 18.6 & 1.2 & 9.6 & neutral & 0.90 & 0.90 & -1.73 & 0.96 & 0.96 & 0.26 & 0.41 & 0.816 & 0 & 0 \\
\hline PhNHEt & 18.2 & 1.9 & 5.0 & neutral & 2.16 & 2.16 & -1.52 & 0.95 & 0.85 & 0.17 & 0.43 & 1.098 & 0 & 0 \\
\hline $\mathrm{PhNO}_{2}$ & 20.0 & 8.6 & 4.1 & neutral & 1.85 & 1.85 & -1.49 & 0.87 & 1.11 & 0.00 & 0.28 & 0.890 & 0 & 0 \\
\hline $\mathrm{PhOH}$ & 18.0 & 5.9 & 14.9 & neutral & 1.47 & 1.47 & -1.56 & 0.81 & 0.89 & 0.60 & 0.30 & 0.775 & 0 & 0 \\
\hline Acridine & 19.6 & 5.4 & 5.8 & neutral & 3.40 & 3.39 & -0.51 & 2.36 & 1.32 & 0.00 & 0.58 & 1.413 & 0 & 0 \\
\hline Aspirin & 18.7 & 4.7 & 11.0 & anion & 1.13 & -2.79 & -2.20 & 0.93 & 3.91 & 0.04 & 3.03 & 1.266 & 0 & 2.122 \\
\hline Flurbiprofen & 19.4 & 2.2 & 7.0 & anion & 3.81 & 0.32 & -1.21 & 1.59 & 4.56 & 0.07 & 3.36 & 1.817 & 0 & 2.538 \\
\hline Ibuprofen & 16.4 & 7.7 & 7.2 & anion & 3.87 & 0.90 & -1.19 & 0.88 & 3.50 & 0.08 & 3.31 & 1.755 & 0 & 2.418 \\
\hline Ketoprofen & 19.5 & 5.5 & 7.8 & anion & 2.77 & -0.34 & -1.32 & 1.80 & 5.49 & 0.01 & 3.39 & 1.956 & 0 & 2.485 \\
\hline Mefenamic acid & 20.3 & 2.5 & 8.1 & anion & 5.12 & 2.05 & -1.17 & 1.80 & 4.71 & 0.09 & 3.14 & 1.899 & 0 & 2.642 \\
\hline
\end{tabular}




\begin{tabular}{|c|c|c|c|c|c|c|c|c|c|c|c|c|c|c|}
\hline Compound & $\begin{array}{c}\boldsymbol{\delta}_{d} \\
\mathrm{MPa}^{1 / 2}\end{array}$ & $\begin{array}{c}\boldsymbol{\delta}_{\boldsymbol{p}} \\
\mathrm{MPa}^{1 / 2}\end{array}$ & $\begin{array}{c}\delta_{h} \\
\mathrm{MPa}^{1 / 2} \\
\end{array}$ & $\begin{array}{c}\text { Charge } \\
\text { state }\end{array}$ & $\begin{array}{l}\text { log } \\
P_{\text {oct }}\end{array}$ & $\begin{array}{l}\log \\
D_{7.4} \\
\end{array}$ & $\begin{array}{l}\text { log } \\
k_{7.4} \\
\end{array}$ & $E$ & $s$ & $A$ & B & $\boldsymbol{v}$ & $J^{+}$ & 5 \\
\hline Naproxen & 18.1 & 6.2 & 9.2 & anion & 3.06 & -0.19 & -1.43 & 1.66 & 5.07 & 0.02 & 3.11 & 1.760 & 0 & 2.426 \\
\hline 4- $\mathrm{BrC}_{6} \mathrm{H}_{4} \mathrm{COOH}$ & 19.9 & 3.7 & 9.2 & anion & 2.86 & -0.57 & -1.16 & 1.15 & 3.47 & 0.04 & 2.61 & 1.085 & 0 & 2.250 \\
\hline $1-\mathrm{C}_{10} \mathrm{H}_{7} \mathrm{COOH}$ & 20.5 & 3.2 & 8.6 & anion & 3.10 & -0.61 & -1.61 & 1.61 & 4.13 & 0.05 & 2.87 & 1.279 & 0 & 2.404 \\
\hline $3-\mathrm{ClC}_{6} \mathrm{H}_{4} \mathrm{COOH}$ & 18.9 & 5.9 & 9.3 & anion & 2.71 & -0.86 & -1.58 & 0.99 & 3.25 & 0.04 & 2.68 & 1.032 & 0 & 2.201 \\
\hline $4-\mathrm{ClC}_{6} \mathrm{H}_{4} \mathrm{COOH}$ & 19.0 & 5.9 & 9.4 & anion & 2.65 & -0.77 & -1.39 & 0.99 & 3.31 & 0.04 & 2.60 & 1.032 & 0 & 2.187 \\
\hline $\mathrm{C}_{6} \mathrm{H}_{5} \mathrm{COOH}$ & 19.2 & 4.3 & 9.9 & anion & 1.96 & -1.24 & -1.16 & 0.88 & 3.05 & 0.02 & 2.75 & 0.910 & 0 & 2.138 \\
\hline $\mathrm{C}_{6} \mathrm{H}_{5}\left(\mathrm{CH}_{2}\right)_{2} \mathrm{COOH}$ & 18.8 & 3.3 & 8.7 & anion & 1.89 & -1.26 & -1.37 & 0.90 & 3.43 & 0.03 & 3.02 & 1.192 & 0 & 2.187 \\
\hline $\mathrm{C}_{6} \mathrm{H}_{5}\left(\mathrm{CH}_{2}\right)_{3} \mathrm{COOH}$ & 18.5 & 2.9 & 8.2 & anion & 2.42 & -0.26 & -1.67 & 0.91 & 3.59 & 0.04 & 3.01 & 1.332 & 0 & 2.218 \\
\hline $\mathrm{C}_{6} \mathrm{H}_{5}\left(\mathrm{CH}_{2}\right)_{4} \mathrm{COOH}$ & 18.3 & 2.6 & 7.8 & anion & 2.85 & 0.00 & -1.63 & 0.92 & 3.63 & 0.04 & 3.10 & 1.471 & 0 & 2.279 \\
\hline $\mathrm{C}_{6} \mathrm{H}_{5}\left(\mathrm{CH}_{2}\right)_{7} \mathrm{COOH}$ & 17.8 & 2.0 & 6.8 & anion & 4.09 & 1.72 & -1.31 & 0.94 & 3.87 & 0.07 & 3.26 & 1.896 & 0 & 2.425 \\
\hline $4-\mathrm{MeC}_{6} \mathrm{H}_{4} \mathrm{CH}_{2} \mathrm{NHMe}$ & 17.2 & 1.6 & 4.6 & cation & 1.96 & -0.57 & -0.63 & 0.63 & 2.64 & 1.47 & 0.00 & 1.260 & 1.262 & 0 \\
\hline 4- $\mathrm{MeC}_{6} \mathrm{H}_{4} \mathrm{CH}_{2} \mathrm{NHEt}$ & 17.2 & 1.4 & 4.4 & cation & 2.38 & -0.26 & -0.63 & 0.61 & 2.69 & 1.48 & 0.00 & 1.401 & 1.264 & 0 \\
\hline 4- $\mathrm{MeC}_{6} \mathrm{H}_{4} \mathrm{CH}_{2} \mathrm{NHPr}$ & 17.1 & 1.3 & 4.1 & cation & 2.96 & 0.38 & -0.56 & 0.59 & 2.68 & 1.45 & 0.00 & 1.542 & 1.260 & 0 \\
\hline 4- $\mathrm{MeC}_{6} \mathrm{H}_{4} \mathrm{CH}_{2} \mathrm{NHBu}$ & 17.0 & 1.2 & 4.0 & cation & 3.49 & 0.91 & -0.44 & 0.57 & 2.68 & 1.46 & 0.00 & 1.683 & 1.240 & 0 \\
\hline 4- $\mathrm{MeC}_{6} \mathrm{H}_{4} \mathrm{CH}_{2} \mathrm{NH}\left(\mathrm{CH}_{2}\right)_{4} \mathrm{Me}$ & 17.0 & 1.1 & 3.8 & cation & 4.26 & 1.58 & -0.08 & 0.55 & 2.66 & 1.41 & 0.00 & 1.824 & 1.252 & 0 \\
\hline $4-\mathrm{MeC}_{6} \mathrm{H}_{4} \mathrm{CH}_{2} \mathrm{NH}\left(\mathrm{CH}_{2}\right)_{5} \mathrm{Me}$ & 16.9 & 1.0 & 3.7 & cation & 4.96 & 2.19 & 0.26 & 0.54 & 2.45 & 1.29 & 0.00 & 1.964 & 1.226 & 0 \\
\hline 4- $\mathrm{MeC}_{6} \mathrm{H}_{4} \mathrm{CH}_{2} \mathrm{NH}\left(\mathrm{CH}_{2}\right)_{6} \mathrm{Me}$ & 16.9 & 1.0 & 3.5 & cation & 5.12 & 2.50 & 0.95 & 0.53 & 2.51 & 1.47 & 0.00 & 2.105 & 1.121 & 0 \\
\hline Acebutolol & 18.0 & 4.3 & 10.5 & cation & 2.02 & -0.10 & -1.01 & 1.45 & 6.69 & 3.62 & 0.00 & 2.777 & 2.296 & 0 \\
\hline Alprenolol & 17.1 & 4.3 & 9.9 & cation & 3.10 & 0.91 & 0.06 & 1.10 & 4.46 & 1.78 & 0.00 & 2.180 & 2.257 & 0 \\
\hline Metoprolol & 17.7 & 7.0 & 10.1 & cation & 1.95 & -0.28 & -0.79 & 1.02 & 5.35 & 2.16 & 0.00 & 2.281 & 2.347 & 0 \\
\hline Oxprenolol & 17.1 & 4.8 & 10.8 & cation & 2.51 & 0.34 & -0.50 & 1.16 & 5.09 & 2.35 & 0.00 & 2.238 & 2.202 & 0 \\
\hline Penbutolol & 17.3 & 2.4 & 9.6 & cation & 4.62 & 2.10 & 0.74 & 0.78 & 4.66 & 1.98 & 0.00 & 2.619 & 1.963 & 0 \\
\hline Pindolol & 18.7 & 3.3 & 11.6 & cation & 1.75 & -0.39 & -0.83 & 1.55 & 4.60 & 2.36 & 0.00 & 2.030 & 2.266 & 0 \\
\hline Propafenone & 17.9 & 3.3 & 9.5 & cation & 3.64 & 1.42 & 0.45 & 1.55 & 5.67 & 2.97 & 0.00 & 2.846 & 2.346 & 0 \\
\hline Propranolol & 19.2 & 7.9 & 10.0 & cation & 3.48 & 1.35 & 0.47 & 1.69 & 4.31 & 2.07 & 0.00 & 2.169 & 2.431 & 0 \\
\hline Timolol & 17.3 & 6.2 & 13.1 & cation & 1.83 & 0.01 & -0.82 & 1.32 & 5.67 & 2.83 & 0.00 & 2.397 & 2.269 & 0 \\
\hline
\end{tabular}


Table 2. Skin permeability coefficients $\left(\log k_{p}\right)$, octanol-water distribution coefficients at pH $7.4\left(\log D_{7.4}\right)$ and Hansen solubility parameters $\left(\delta_{d}, \delta_{p}, \delta_{h}\right)$ of 168 substances. Compounds which are undissociated to an extent of more than $80 \%$ at $\mathrm{pH} 7.4$ are referred to as neutral. Those which are undissociated less than $20 \%$ at $\mathrm{pH} 7.4$ are referred to as anions or cations. All other compounds are partially dissociated (20-80 \% undissociated) and labelled with "a/n"

(anionic/neutral) or "c/n" (cationic/neutral).

\begin{tabular}{|c|c|c|c|c|c|c|c|c|c|}
\hline Compound & $\delta_{d}$ & $\delta_{p}$ & $\delta_{h}$ & Ref. & $\begin{array}{l}\log k_{p} \\
(\mathrm{~cm} / \mathrm{h})\end{array}$ & Ref. & $\begin{array}{l}\text { Charge } \\
\text { state }\end{array}$ & $\begin{array}{l}\log \\
D_{7.4}\end{array}$ & Ref. \\
\hline 1,1,1-Trichloroethane & 17.7 & 9.9 & 3.5 & j & -2.34 & $a, b$ & neutral & 2.49 & $b, c$ \\
\hline 1,3-Dichloropropene & 16.6 & 8.2 & 2.9 & j & -2.00 & a & neutral & 1.82 & 0 \\
\hline 17-Hydroxyprogesterone & 18.4 & 4.2 & 9.2 & j & -3.22 & $d, e, a$ & neutral & 2.74 & d,e \\
\hline 2,3-Butanediol & 15.7 & 7.8 & 21.0 & j & -4.17 & $d, e, a, f, p$ & neutral & -0.92 & $d, e, c, f$ \\
\hline 2,4,6-Trichlorophenol & 19.6 & 8.7 & 13.1 & j & -1.23 & $d, e, a, f, b$ & anion & 2.70 & 0 \\
\hline 2,4-Dichlorophenol & 21.3 & 8.3 & 13.6 & j & -1.22 & $d, e, a, f, b$ & neutral & 3.10 & $d, e, c, f, b$ \\
\hline 2-Butoxyethanol & 15.8 & 4.9 & 13.2 & j & -2.85 & a & neutral & 0.80 & i \\
\hline 2-Chlorophenol & 20.3 & 5.5 & 13.9 & $\mathrm{k}$ & -1.36 & $d, e, a, f, b, p$ & neutral & 2.16 & $d, e, c, f, b$ \\
\hline 2-Cresol & 18.2 & 4.9 & 13.9 & j & -1.68 & $d, e, a, f, b, p$ & neutral & 1.97 & $d, e, c, f, b$ \\
\hline 2-Ethoxyethanol & 16.1 & 9.2 & 14.3 & $\mathrm{k}$ & -3.48 & $d, e, a, f, b, p$ & neutral & -0.47 & $d, e, c, f, b$ \\
\hline 2-Heptanone & 16.2 & 5.7 & 4.1 & k & -2.00 & a & neutral & 1.97 & i \\
\hline 2-Hexanone & 15.3 & 6.1 & 4.1 & k & -2.35 & a & neutral & 1.44 & $\mathrm{i}$ \\
\hline 2-Hydroxypropyl nicotinate & 16.2 & 8.5 & 14.1 & j & -3.99 & $p$ & neutral & 0.27 & i \\
\hline 2-Methoxyethanol & 16.2 & 9.2 & 16.4 & $\mathrm{k}$ & -3.73 & a & neutral & -0.80 & $\mathrm{i}$ \\
\hline 2-Naphthol & 19.7 & 6.3 & 12.3 & j & -1.47 & $d, e, a, f, b, p$ & neutral & 2.78 & $d, e, c, f, b$ \\
\hline 2-Pentanone & 15.4 & 7.1 & 4.3 & j & -2.60 & a & neutral & 0.91 & i \\
\hline 2-Phenylethanol & 18.2 & 4.3 & 12.9 & j & -1.71 & $a, b, f, p$ & neutral & 1.50 & 0 \\
\hline 2-Toluidine & 19.4 & 5.8 & 9.4 & $\mathrm{k}$ & -1.44 & a & neutral & 1.40 & i \\
\hline 3,4-Xylenol & 17.0 & 4.2 & 12.9 & j & -1.32 & $d, e, a, f, b, p$ & neutral & 2.23 & $q$ \\
\hline 3-Cresol & 18.0 & 5.1 & 12.9 & $\mathrm{k}$ & -1.70 & $d, e, a, f, b, p$ & neutral & 1.96 & $q$ \\
\hline 3-Nitrophenol & 19.9 & 11.9 & 14.7 & j & -2.25 & $d, e, a, f, b$ & neutral & 1.96 & $q$ \\
\hline 3-Xylene & 17.3 & 0.9 & 0.0 & j & -1.10 & a & neutral & 3.14 & i \\
\hline 4-Bromophenol & 21.3 & 4.9 & 13.9 & j & -1.32 & $d, e, a, f, b, p$ & neutral & 2.59 & $d, e, c, f, b$ \\
\hline 4-Chloro-3,5-xylenol & 20.9 & 4.0 & 12.4 & j & -1.13 & $d, e, a, f, b, p$ & neutral & 3.39 & $d, e, c, f, b$ \\
\hline 4-Chloro-m-cresol & 20.3 & 6.5 & 13.3 & j & -0.78 & $\mathrm{p}$ & neutral & 2.88 & i \\
\hline 4-Chloro-m-phenylenediamine & 19.0 & 5.2 & 12.7 & j & -2.98 & $\mathrm{p}$ & neutral & 0.84 & $\mathrm{i}, \mathrm{o}$ \\
\hline 4-Chloro-o-cresol & 20.3 & 6.5 & 13.3 & j & -1.25 & $d, e, a, f, b$ & neutral & 3.10 & $d, e, c, f, b$ \\
\hline 4-Chlorophenol & 19.3 & 7.5 & 14.3 & j & -1.32 & $d, e, a, f, b, p$ & neutral & 2.39 & $d, e, c, f, b$ \\
\hline 4-Cresol & 18.3 & 4.9 & 13.9 & j & -1.63 & $d, e, a, f, b, p$ & neutral & 1.94 & $d, e, c, f, b$ \\
\hline 4-Ethylphenol & 18.0 & 4.2 & 12.9 & j & -1.34 & $d, e, a, f, b, p$ & neutral & 2.46 & $d, e, c, f, b$ \\
\hline 4-(Hydroxymethyl)phenol & 19.3 & 7.0 & 19.8 & j & -2.70 & $\mathrm{p}$ & neutral & 0.40 & i \\
\hline 4-Hydroxy-methylphenylacetate & 20.5 & 5.0 & 15.1 & j & -1.70 & $p$ & neutral & -1.77 & $\mathrm{i}$ \\
\hline 4-Hydroxyphenylacetamide & 19.9 & 5.8 & 17.1 & j & -3.33 & $\mathrm{p}$ & neutral & 0.18 & i \\
\hline 4- $\mathrm{MeC}_{6} \mathrm{H}_{4} \mathrm{CH}_{2} \mathrm{NH}\left(\mathrm{CH}_{2}\right)_{4} \mathrm{Me}$ & 17.0 & 1.1 & 3.8 & j & -2.44 & $\mathrm{p}$ & cation & 1.58 & $q$ \\
\hline 4- $\mathrm{MeC}_{6} \mathrm{H}_{4} \mathrm{CH}_{2} \mathrm{NH}\left(\mathrm{CH}_{2}\right)_{5} \mathrm{Me}$ & 16.9 & 1.0 & 3.7 & j & -2.31 & $p$ & cation & 2.19 & $q$ \\
\hline 4- $\mathrm{MeC}_{6} \mathrm{H}_{4} \mathrm{CH}_{2} \mathrm{NH}\left(\mathrm{CH}_{2}\right)_{6} \mathrm{Me}$ & 16.9 & 1.0 & 3.5 & j & -2.14 & $\mathrm{p}$ & cation & 2.50 & $q$ \\
\hline 4- $\mathrm{MeC}_{6} \mathrm{H}_{4} \mathrm{CH}_{2} \mathrm{NHBu}$ & 17.0 & 1.2 & 4.0 & j & -3.16 & $\mathrm{p}$ & cation & 0.91 & $q$ \\
\hline 4- $\mathrm{MeC}_{6} \mathrm{H}_{4} \mathrm{CH}_{2} \mathrm{NHEt}$ & 17.2 & 1.4 & 4.4 & j & -3.41 & $\mathrm{p}$ & cation & -0.26 & $q$ \\
\hline 4- $\mathrm{MeC}_{6} \mathrm{H}_{4} \mathrm{CH}_{2} \mathrm{NHMe}$ & 17.2 & 1.6 & 4.6 & j & -4.15 & $\mathrm{p}$ & cation & -0.57 & $q$ \\
\hline 4- $\mathrm{MeC}_{6} \mathrm{H}_{4} \mathrm{CH}_{2} \mathrm{NHPr}$ & 17.1 & 1.3 & 4.1 & j & -3.41 & $\mathrm{p}$ & cation & 0.38 & $q$ \\
\hline 4-Methyl-2-pentanol & 15.1 & 4.0 & 12.6 & j & -2.33 & a & neutral & 1.57 & i \\
\hline 4-Nitrophenol & 19.9 & 11.9 & 14.7 & j & -2.25 & $d, e, a, f, b$ & $a / n$ & 1.94 & $d, e, c, f, b$ \\
\hline $\begin{array}{l}\text { 5,5-Diethylbarbituric acid } \\
\text { (Barbital) }\end{array}$ & 16.7 & 8.5 & 8.7 & j & -3.90 & $d, e, a, f, b, p$ & $a / n$ & 0.69 & $\mathrm{i}, \mathrm{o}$ \\
\hline $\begin{array}{l}\text { 5-Ethyl-5-(3-methylbutyl) } \\
\text { barbituric acid (Amobarbital) }\end{array}$ & 16.4 & 6.5 & 7.6 & j & -2.59 & $d, e, a, f, b, p$ & $a / n$ & 2.06 & i,o \\
\hline $\begin{array}{l}\text { 5-Ethyl-5-butylbarbituric acid } \\
\text { (Butobarbital) }\end{array}$ & 16.6 & 7.0 & 7.9 & j & -3.65 & $d, e, a, f, p$ & $a / n$ & 1.71 & $\mathrm{i}, \mathrm{o}$ \\
\hline $\begin{array}{l}\text { 5-Ethyl-5-phenylbarbituric acid } \\
\text { (Phenobarbital) }\end{array}$ & 18.2 & 4.3 & 6.7 & j & -3.29 & $d, e, a, f, b, p$ & $a / n$ & -3.11 & $\mathrm{i}, \mathrm{o}$ \\
\hline
\end{tabular}




\begin{tabular}{|c|c|c|c|c|c|c|c|c|c|}
\hline Compound & $\delta_{d}$ & $\delta_{p}$ & $\delta_{h}$ & Ref. & $\begin{array}{c}\log k_{p} \\
(\mathrm{~cm} / \mathrm{h})\end{array}$ & Ref. & $\begin{array}{l}\text { Charge } \\
\text { state }\end{array}$ & $\begin{array}{l}\log \\
D_{7.4}\end{array}$ & Ref. \\
\hline 5-Fluorouracil & 19.6 & 13.3 & 11.0 & j & -3.26 & $p$ & $a / n$ & -1.64 & $\mathrm{i}$ \\
\hline 8-Methoxypsoralen & 21.9 & 6.6 & 8.3 & j & -1.56 & $\mathrm{p}$ & neutral & 1.52 & i \\
\hline Acetic acid & 14.5 & 8.0 & 13.5 & $\mathrm{k}$ & -3.21 & $\mathrm{a}$ & anion & -2.90 & 0 \\
\hline Acrylic acid & 16.7 & 6.2 & 12.1 & j & -3.05 & $\mathrm{a}$ & anion & -2.90 & 0 \\
\hline Acrylonitrile & 16.0 & 12.8 & 6.8 & k & -2.87 & a & neutral & 0.19 & i \\
\hline Aldosterone & 19.0 & 5.4 & 13.1 & j & -4.69 & $d, e, a, f, b, p$ & neutral & 1.08 & $d, e, c, f, b$ \\
\hline Allyl alcohol & 15.3 & 7.1 & 16.8 & j & -2.95 & a & neutral & 0.17 & i \\
\hline Aniline & 18.6 & 1.2 & 9.6 & j & -1.83 & $a, b, p$ & neutral & 0.91 & $b$ \\
\hline Anisole & 17.2 & 3.7 & 5.1 & j & -1.25 & $a, f, b, p$ & neutral & 2.11 & $c, f, b$ \\
\hline Benzaldehyde & 18.8 & 8.0 & 6.7 & j & -0.91 & $a, f, b, p$ & neutral & 1.48 & $c, f, b$ \\
\hline Benzene & 15.5 & 0.0 & 0.0 & j & -0.86 & $a, f, b, p$ & neutral & 2.12 & $c, f, b$ \\
\hline Benzyl alcohol & 18.4 & 6.3 & 13.7 & $\mathrm{k}$ & -1.88 & $d, e, a, f, b, p$ & neutral & 1.10 & $d, e, c, f, b, q$ \\
\hline Benzyl nicotinate & 18.3 & 3.0 & 7.5 & j & -1.31 & $\mathrm{p}$ & neutral & 2.48 & $\mathrm{i}$ \\
\hline Butanoic acid & 16.7 & 4.7 & 10.6 & j & -3.00 & $\mathrm{~d}, \mathrm{e}, \mathrm{a}$ & anion & -1.91 & 0 \\
\hline Butanone & 15.3 & 8.4 & 4.7 & j & -2.18 & $d, e, a, f, p$ & neutral & 0.29 & $d, e, c, f$ \\
\hline Butyl acrylate & 15.6 & 3.4 & 7.0 & j & -2.00 & $\mathrm{a}$ & neutral & 2.39 & i \\
\hline Butyl nicotinate & 16.7 & 3.1 & 7.7 & j & -1.30 & $\mathrm{p}$ & neutral & 2.32 & i \\
\hline $\mathrm{C}_{6} \mathrm{H}_{5}\left(\mathrm{CH}_{2}\right)_{2} \mathrm{COOH}$ & 18.8 & 3.3 & 8.7 & j & -1.57 & $p$ & neutral & -1.26 & $q$ \\
\hline $\mathrm{C}_{6} \mathrm{H}_{5}\left(\mathrm{CH}_{2}\right)_{3} \mathrm{COOH}$ & 18.5 & 2.9 & 8.2 & j & -1.49 & $p$ & neutral & -0.26 & $q$ \\
\hline $\mathrm{C}_{6} \mathrm{H}_{5}\left(\mathrm{CH}_{2}\right)_{4} \mathrm{COOH}$ & 18.3 & 2.6 & 7.8 & j & -0.94 & $p$ & neutral & 0.00 & $q$ \\
\hline $\mathrm{C}_{6} \mathrm{H}_{5}\left(\mathrm{CH}_{2}\right)_{7} \mathrm{COOH}$ & 17.8 & 2.0 & 6.8 & j & -0.50 & $p$ & neutral & 1.72 & $q$ \\
\hline $\mathrm{C}_{6} \mathrm{H}_{5} \mathrm{COOH}$ & 19.2 & 4.3 & 9.9 & j & -1.55 & $\mathrm{p}$ & anion & -1.24 & $q$ \\
\hline Caffeine & 20.8 & 13.3 & 12.9 & j & -3.87 & $a, f, p$ & neutral & -0.05 & $c, f$ \\
\hline Catechol & 20.0 & 11.3 & 21.8 & k & -2.77 & $\mathrm{a}$ & neutral & 0.88 & $\mathrm{i}$ \\
\hline Chlorpheniramine & 17.3 & 5.1 & 6.5 & j & -2.66 & $d, e, a, b$ & cation & 1.04 & 0 \\
\hline Cortexolone & 18.8 & 4.6 & 12.5 & j & -4.13 & $d, e, a, b$ & neutral & 2.52 & $d, e, b$ \\
\hline Cortexone & 18.4 & 4.2 & 9.2 & j & -3.35 & $d, e, a, b$ & neutral & 2.88 & $d, e, b$ \\
\hline Corticosterone & 18.6 & 4.6 & 12.4 & j & -3.75 & $d, e, a, f, b, p$ & neutral & 1.94 & $d, e, c, f, b$ \\
\hline Cyclohexanone & 15.9 & 7.5 & 4.4 & j & -2.74 & a & neutral & 0.76 & $\mathrm{i}$ \\
\hline Dexamethasone & 18.6 & 4.7 & 14.7 & j & -4.03 & $a, f, p$ & neutral & 1.91 & $c, f$ \\
\hline Diclofenac & 21.3 & 4.5 & 8.2 & j & -2.31 & $a, f, b$ & anion & 1.44 & 0 \\
\hline Diethyl ether & 14.7 & 2.8 & 5.5 & j & -2.05 & $d, e, a, f, b, p$ & neutral & 0.83 & $d, e, f, b$ \\
\hline Diethylamine & 14.9 & 1.4 & 5.5 & j & -2.75 & a & cation & -2.25 & 0 \\
\hline Diethylcarbamazine & 16.4 & 8.1 & 9.3 & j & -3.46 & $d, e, a, b, p$ & $\mathrm{c} / \mathrm{n}$ & 0.08 & 0 \\
\hline Digitoxin & 18.7 & 3.0 & 14.6 & j & -4.79 & $d, e, a, b, p$ & neutral & 2.44 & $\mathrm{i}$ \\
\hline Dimethyl acetamide & 16.8 & 11.5 & 10.2 & $\mathrm{k}$ & -2.80 & $\mathrm{a}$ & neutral & 0.21 & 0 \\
\hline Dimethyl formamide & 17.4 & 13.7 & 11.3 & k & -1.98 & a & neutral & -0.83 & 0 \\
\hline Dimethyl sulfoxide & 18.4 & 16.4 & 10.2 & k & -1.80 & a & neutral & -1.35 & $\mathrm{i}$ \\
\hline Ephedrine & 17.2 & 3.4 & 11.9 & j & -2.22 & $d, e, a, f, b$ & cation & -0.93 & 0 \\
\hline Estradiol & 18.4 & 3.0 & 13.1 & j & -2.45 & $d, e, a, f, b, p$ & neutral & 2.91 & $d, e, f, b$ \\
\hline Estriol & 18.7 & 3.8 & 16.2 & j & -4.40 & $d, e, a, b$ & neutral & 2.47 & $d, e, b$ \\
\hline Estrone & 19.6 & 4.0 & 9.7 & j & -2.44 & $d, e, a, b$ & neutral & 2.76 & $d, e, b$ \\
\hline Ethanol & 15.8 & 8.8 & 19.4 & k & -2.96 & $d, e, a, f, b, p$ & neutral & -0.31 & $d, e, c, f, b$ \\
\hline Ethyl acrylate & 15.5 & 7.1 & 5.5 & k & -2.39 & a & neutral & 1.32 & i \\
\hline Ethyl benzene & 17.3 & 0.9 & 0.0 & j & 0.62 & $d, e, a, f, p$ & neutral & 3.15 & $d, e, c, f$ \\
\hline Ethyl formate & 13.2 & 10.6 & 7.8 & j & -3.01 & $\mathrm{a}$ & neutral & 0.30 & i \\
\hline Ethyl nicotinate & 16.8 & 3.9 & 8.6 & j & -1.72 & $p$ & neutral & 1.30 & i \\
\hline Ethylene dichloride & 17.1 & 6.5 & 3.1 & j & -2.00 & $a$ & neutral & 1.41 & i \\
\hline Ethylene glycol & 17.0 & 11.0 & 26.0 & k & -4.07 & a & neutral & -1.69 & $\mathrm{i}$ \\
\hline Etorphine & 19.8 & 3.5 & 9.9 & j & -2.44 & $d, e, a, b$ & cation & 1.92 & 0 \\
\hline Fentanyl & 18.7 & 4.5 & 6.2 & j & -2.26 & $d, e, a, f, b$ & cation & 2.61 & 0 \\
\hline Fluocinonide & 18.1 & 4.3 & 9.8 & j & -2.77 & $d, e, a, f, b, p$ & neutral & 3.19 & $d, e, c, f, b$ \\
\hline Formaldehyde & 10.7 & 18.3 & 10.1 & j & -2.65 & $\mathrm{a}$ & neutral & 0.35 & 0 \\
\hline Glycerol trinitrate & 17.8 & 14.6 & 10.0 & j & -1.65 & $p$ & neutral & 2.15 & i \\
\hline Heptanoic acid & 16.6 & 3.0 & 8.5 & j & -1.70 & $\mathrm{~d}, \mathrm{e}, \mathrm{a}$ & anion & -0.36 & 0 \\
\hline
\end{tabular}




\begin{tabular}{|c|c|c|c|c|c|c|c|c|c|}
\hline Compound & $\delta_{d}$ & $\delta_{p}$ & $\delta_{h}$ & Ref. & $\begin{array}{l}\log k_{p} \\
(\mathrm{~cm} / \mathrm{h})\end{array}$ & Ref. & $\begin{array}{l}\text { Charge } \\
\text { state }\end{array}$ & $\begin{array}{l}\log \\
D_{7.4}\end{array}$ & Ref. \\
\hline Hexachloroethane & 19.7 & 7.3 & 4.3 & j & -1.40 & $a$ & neutral & 4.47 & $\mathrm{i}$ \\
\hline Hexanoic acid & 16.6 & 3.4 & 9.0 & j & -1.85 & $d, e, a$ & anion & -0.87 & 0 \\
\hline Hexyl nicotinate & 16.6 & 2.6 & 7.1 & $\mathrm{j}$ & -1.27 & $\mathrm{p}$ & neutral & 3.34 & $\mathrm{i}$ \\
\hline Hydrocortisone & 19.0 & 4.9 & 15.1 & $j, I$ & -4.43 & $d, e, a, f, b, p$ & neutral & 1.56 & $d, e, c, f, b$ \\
\hline $\begin{array}{l}\text { Hydrocortisone } 21-(6- \\
\text { hydroxy)hexanoate }\end{array}$ & 18.1 & 3.6 & 11.6 & j & -2.92 & $d, e, a, f, b, p$ & neutral & 2.79 & $d, e, c, f, b$ \\
\hline $\begin{array}{l}\text { Hydrocortisone } 21-(\mathrm{N}, \mathrm{N}- \\
\text { dimethyl)succinamate }\end{array}$ & 18.1 & 4.4 & 9.9 & j & -4.17 & $d, e, a, f, b, p$ & neutral & 2.03 & $d, e, c, f, b$ \\
\hline Hydrocortisone 21-hemipimelate & 18.3 & 3.5 & 10.2 & j & -2.73 & $d, e, a, f, b, p$ & anion & 0.25 & 0 \\
\hline $\begin{array}{l}\text { Hydrocortisone } 21 \text { - } \\
\text { hemisuccinate }\end{array}$ & 18.5 & 3.9 & 10.9 & j & -3.18 & $d, e, a, f, b, p$ & anion & -0.47 & 0 \\
\hline Hydrocortisone 21-hexanoate & 17.8 & 3.4 & 9.0 & j & -1.74 & $d, e, a, f, b, p$ & neutral & 4.04 & $d, e, c, f, b$ \\
\hline $\begin{array}{l}\text { Hydrocortisone } 21- \\
\text { methylpimelate }\end{array}$ & 15.9 & 3.3 & 9.5 & j & -2.27 & $d, e, a, f, b, p$ & neutral & 3.50 & $d, e, c, f, b$ \\
\hline $\begin{array}{l}\text { Hydrocortisone } 21 \text { - } \\
\text { methylsuccinate }\end{array}$ & 18.0 & 3.7 & 10.1 & j & -3.68 & $d, e, a, f, b, p$ & neutral & 3.58 & $d, e, c, f, b$ \\
\hline Hydrocortisone 21-octanoate & 17.7 & 3.1 & 8.6 & j & -1.21 & $d, e, a, f, b, p$ & neutral & 5.49 & $d, e, c, f, b$ \\
\hline Hydrocortisone 21-pimelamate & 18.1 & 3.8 & 10.2 & j & -2.93 & $d, e, a, f, b, p$ & neutral & 2.31 & $d, e, c, f, b$ \\
\hline Hydrocortisone 21-propionate & 17.9 & 3.9 & 9.6 & j & -2.47 & $d, e, a, f, b, p$ & neutral & 3.00 & $d, e, c, f, b$ \\
\hline Hydrocortisone 21-succinamate & 18.3 & 4.3 & 10.8 & j & -4.59 & $d, e, a, f, b, p$ & neutral & 1.43 & $d, e, c, f, b$ \\
\hline Hydroxypregnenolone & 18.4 & 3.6 & 12.1 & j & -3.22 & $d, e, a, b$ & neutral & 3.00 & $\mathrm{~d}, \mathrm{e}, \mathrm{b}$ \\
\hline Indometacin & 19.9 & 5.1 & 8.7 & j & -2.44 & $a, f, b$ & anion & 0.98 & 0 \\
\hline Isoamyl alcohol & 15.3 & 4.6 & 13.5 & j & -2.00 & $\mathrm{a}$ & neutral & 1.22 & $\mathrm{i}$ \\
\hline Isobutanol & 15.1 & 5.7 & 15.9 & $\mathrm{k}$ & -2.65 & $a$ & neutral & 0.68 & 0 \\
\hline Isoquinoline & 18.9 & 6.6 & 6.5 & j & -1.72 & $d, e, a, f, b, p$ & neutral & 2.07 & $d, e, c, f, b$ \\
\hline Lidocaine & 18.5 & 5.0 & 6.7 & j & -2.09 & $a, f, b$ & $\mathrm{c} / \mathrm{n}$ & 1.67 & 0 \\
\hline Mannitol & 18.6 & 10.7 & 32.4 & j & -4.86 & $\mathrm{p}$ & neutral & -3.26 & $\mathrm{i}$ \\
\hline Meperidine & 16.9 & 4.0 & 7.2 & j & -2.43 & $d, e, a, b$ & cation & 1.62 & 0 \\
\hline Methacrylic acid & 16.9 & 5.0 & 10.9 & j & -2.58 & a & anion & -2.20 & 0 \\
\hline Methanol & 15.1 & 12.3 & 22.3 & k & -3.14 & $d, e, a, f, b, p$ & neutral & -0.74 & $d, e$ \\
\hline Methyl 4-hydroxybenzoate & 18.2 & 5.6 & 14.7 & j & -1.92 & $d, e, a, f, b, p$ & neutral & 1.96 & $d, e, c, f, b$ \\
\hline Methyl acrylate & 15.3 & 6.7 & 9.4 & $\mathrm{k}$ & -2.68 & a & neutral & 0.79 & i \\
\hline Methyl nicotinate & 16.8 & 4.4 & 9.2 & j & -2.21 & $\mathrm{p}$ & neutral & 0.88 & $\mathrm{i}$ \\
\hline Methylene chloride & 17.8 & 6.4 & 6.1 & $\mathrm{k}$ & -2.74 & $a$ & neutral & 1.53 & $\mathrm{i}$ \\
\hline Methyltriglycol nicotinate & 16.6 & 3.7 & 8.9 & j & -3.27 & $\mathrm{p}$ & neutral & & \\
\hline Monomethylhydrazine & 16.2 & 8.7 & 14.8 & $\mathrm{k}$ & -3.75 & $a$ & cation & -2.82 & 0 \\
\hline N,N-Dimethylaniline & 18.0 & 6.3 & 6.3 & j & -1.70 & a & neutral & 2.33 & i \\
\hline Naproxen & 18.1 & 6.2 & 9.2 & $\mathrm{j}, \mathrm{l}, \mathrm{m}$ & -2.84 & $d, e, a, f, b$ & anion & 0.35 & 0 \\
\hline n-Butanol & 16.0 & 5.7 & 15.8 & k & -2.52 & $d, e, a, f, b, p$ & neutral & 0.88 & $d, e, c, f, b$ \\
\hline n-Decanol & 16.0 & 2.6 & 10.2 & j & -0.93 & $d, e, a, f, b, p$ & neutral & 4.20 & $d, e, c, f$ \\
\hline n-Heptanol & 15.9 & 3.5 & 11.9 & j & -1.41 & $d, e, a, f, b, p$ & neutral & 2.62 & $d, e, c, f, b$ \\
\hline n-Hexanol & 15.8 & 4.0 & 12.6 & j & -1.71 & $d, e, a, f, b, p$ & neutral & 2.03 & $d, e, c, f, b$ \\
\hline Nicotine & 20.5 & 6.6 & 10.7 & j & -1.72 & $d, e, a, f, b$ & cation & -0.62 & 0 \\
\hline Nitroglycerine & 16.2 & 17.8 & 5.9 & k & -1.96 & $d, e, a, b$ & neutral & 1.87 & $d, e, c, b$ \\
\hline n-Methyl-2-pyrrolidone & 18.0 & 11.5 & 8.5 & j & -1.80 & a & neutral & -0.40 & i \\
\hline n-Nonanol & 16.0 & 2.9 & 10.7 & j & -1.10 & $d, e, a, f, b, p$ & neutral & 3.80 & $d, e, f, b$ \\
\hline n-Octanol & 15.9 & 3.2 & 11.2 & j & -1.11 & $d, e, a, f, b, p$ & neutral & 3.07 & $d, e, c, f, b$ \\
\hline n-Pentanol & 15.7 & 4.6 & 13.6 & j & -2.10 & $d, e, a, f, b, p$ & neutral & 1.51 & $d, e, c, f, b$ \\
\hline n-Propanol & 16.0 & 6.8 & 17.4 & k & -2.77 & $d, e, a, f, b, p$ & neutral & 0.28 & $d, e, c, f, b$ \\
\hline Octanoic acid & 15.1 & 3.3 & 8.2 & k & -1.60 & a & anion & 0.15 & 0 \\
\hline o-Phenylenediamine & 19.5 & 0.8 & 13.4 & j & -3.14 & $\mathrm{p}$ & neutral & 0.05 & $\mathrm{i}$ \\
\hline Ouabain & 18.9 & 4.2 & 21.2 & j & -6.11 & $a, b, p$ & neutral & -2.85 & $c, b$ \\
\hline Pentanoic acid & 16.7 & 4.0 & 9.7 & j & -2.70 & $\mathrm{a}$ & anion & -1.39 & 0 \\
\hline Phenol & 18.0 & 5.9 & 14.9 & $\mathrm{k}$ & -1.93 & $d, e, a, f, b, p$ & neutral & 1.46 & $d, e, c, f, b$ \\
\hline Phenylglycidyl ether & 18.2 & 4.3 & 6.7 & j & -2.84 & a & neutral & 1.74 & i \\
\hline
\end{tabular}




\begin{tabular}{|c|c|c|c|c|c|c|c|c|c|}
\hline Compound & $\delta_{d}$ & $\delta_{p}$ & $\delta_{h}$ & Ref. & $\begin{array}{c}\log k_{p} \\
(\mathrm{~cm} / \mathrm{h})\end{array}$ & Ref. & $\begin{array}{l}\text { Charge } \\
\text { state }\end{array}$ & $\begin{array}{l}\log \\
D_{7.4} \\
\end{array}$ & Ref. \\
\hline Piroxicam ${ }^{c}$ & 18.9 & 7.1 & 13.6 & $\bar{j}$ & -2.46 & $p$ & neutral & 1.68 & $\mathrm{i}$ \\
\hline p-Phenylenediamine & 19.5 & 0.8 & 13.4 & j & -3.42 & $p$ & neutral & -0.71 & $\mathrm{i}$ \\
\hline Pregnenolone & 18.0 & 3.2 & 8.7 & j & -2.82 & $d, e, a$ & neutral & 3.13 & $d, e, b$ \\
\hline Progesterone & 18.0 & 3.8 & 3.7 & j & -2.08 & $d, e, a, f, b, p$ & neutral & 3.84 & $d, e, c, f, b$ \\
\hline Propionic acid & 14.7 & 5.3 & 12.4 & k & -2.94 & a & anion & -2.39 & 0 \\
\hline Propylene oxide & 15.2 & 8.6 & 6.7 & k & -3.05 & $\mathrm{a}$ & neutral & 0.13 & $\mathrm{i}$ \\
\hline Resorcinol & 18.0 & 8.4 & 21.0 & k & -3.50 & $d, e, a, f, b, p$ & neutral & 0.80 & $d, e, c, f, b$ \\
\hline Salicylic acid & 19.4 & 10.1 & 17.4 & k & -2.32 & $d, e, a, f, b$ & anion & -1.14 & 0 \\
\hline Scopolamine & 19.2 & 4.9 & 12.3 & j & -4.30 & $d, e, a, f, b$ & $c / n$ & 0.05 & 0 \\
\hline Styrene & 17.6 & 0.6 & 0.0 & j & -0.19 & $d, e, a, f$ & neutral & 2.95 & $d, e, c, f$ \\
\hline Sucrose & 17.7 & 7.5 & 27.8 & j & -5.28 & $d, e, a, b$ & neutral & -2.74 & $d, e, c, b$ \\
\hline Testosterone & 18.3 & 3.6 & 9.3 & j & -2.74 & $d, e, a, f, b, p$ & neutral & 3.31 & $d, e, c, f, b$ \\
\hline Thymol & 16.5 & 3.2 & 11.4 & $\mathrm{j}$ & -1.15 & $d, e, a, f, p$ & neutral & 3.33 & $d, e, c, f, b$ \\
\hline Toluene & 17.5 & 1.0 & 0.0 & j & -0.04 & $d, e, a, p$ & neutral & 2.74 & $d, e, c$ \\
\hline Triglycol nicotinate & 16.4 & 5.6 & 13.3 & j & -4.52 & $\mathrm{p}$ & neutral & & \\
\hline Urea & 20.9 & 18.7 & 26.4 & k & -4.37 & $\mathrm{p}$ & neutral & -1.66 & $\mathrm{i}$ \\
\hline Vinyl acetate & 16.0 & 7.2 & 5.9 & k & -2.73 & $\mathrm{a}$ & neutral & 0.73 & $\mathrm{i}$ \\
\hline
\end{tabular}

a) Reference [54] (Santos-Filho et al., 2004), b) Reference [55] (Wilschut et al., 1995), c) Reference [56] (Hansch and Leo, 1979), d) Reference [57] (Flynn, 1990), e) Reference [58] (Barratt, 1995), f) Reference [59] (Johnson et al., 1997), g) Reference [60] (Pugh et al., 2000), h) Reference [61] (Hansch et al., 1995), i) Calculated with the software ACD/ChemSketch Freeware (version 10.00, Advanced Chemistry Development, Inc., Toronto, ON, Canada, www.acdlabs.com, 2006), j) Calculated by the group contribution method accordingt to Hoftyzer, Van Krevelen [40] (van Krevelen, 1990), k) Reference [18] (Hansen, 2007a), I) Reference [62] (Dwan`Isa, 2005), m) Reference [63] (Bustamante et al., 1998), n) Reference [64] (Peña et al., 2000), o) ChemSpider (Royal Society of Chemistry, London, UK) (www.chemspider.com), p) Reference [53] Zhang et al., 2012), q) Reference [11] (Zhang et al., 2011)

(C)2014 by the authors; licensee IAPC, Zagreb, Croatia. This article is an open-access article distributed under the terms and conditions of the Creative Commons Attribution license (http://creativecommons.org/licenses/by/3.0/) (cc) EY 